\title{
Exploring the combustion chemistry of anisole in laminar counterflow diffusion-flames under oxy-fuel conditions
}

Bingjie Chen ${ }^{\text {a,* }}$, Maximillian Hellmuth ${ }^{\text {a }}$, Sebastian Faller ${ }^{\text {a }}$, Laurenz May ${ }^{\text {a }}$, Peng Liu ${ }^{\text {b }}$, Liming Cai $^{c}$, William L. Roberts ${ }^{b}$, Heinz Pitsch ${ }^{a}$

a Institute for Combustion Technology, RWTH Aachen University, Templergraben 64, 52056 Aachen, Germany b Clean Combustion Research Center, King Abdullah University of Science and Technology, Thuwal, 239556900, Saudi Arabia

c School for Automotive Studies, Tongji University, 201804, Shanghai, China

\section{Abstract:}

Biomass combustion under oxy-fuel conditions, i.e., burning biomass by using $\mathrm{CO}_{2} / \mathrm{O}_{2}$ mixtures as oxidizer instead of air, is a promising approach to mitigate climate change by recycling $\mathrm{CO}_{2}$ from the exhaust gas. Understanding oxy-fuel biomass combustion chemistry can further help to achieve higher efficiency and lower emissions in future design concepts. In this work, we investigated the combustion chemistry of anisole, a potential component of surrogates for biomass and volatiles, in two selected laminar counterflow diffusion flames under oxy-fuel conditions. A time-of-flight molecular-beam mass-spectrometer (ToF-MBMS) and a gas chromatograph with a mass spectrometer (GC-MS) were used to analyze the chemical compositions of the gaseous samples at various flame positions. The combined measurements allowed us to identify and quantify over 40 species, including many polycyclic aromatic hydrocarbons (PAH) and oxygenated polycyclic aromatic hydrocarbons (OPAH). Comparing the experimental results to numerical simulations using the latest kinetic model from Yuan et al. (Combust. Flame 2019, 201, 187-199), we found that some of the aromatic hydrocarbons (e.g., phenylacetylene, styrene, and ethylbenzene), PAH molecules, (e.g., naphthalene and

\footnotetext{
* Corresponding author email: b.chen@itv.rwth-aachen.de
} 
acenaphthylene), and OPAH molecules (e.g., cresol, benzofuran, and dibenzofuran) were overpredicted by the kinetic model. The model analysis indicated that the reaction rate coefficients in PAH and OPAH chemistry may be responsible. Tentative kinetic model updates showed improvement on the predictions of benzofuran, naphthalene, and acenaphthylene. In summary, this work provides comprehensive speciation datasets from two measurement techniques, examines the latest anisole kinetic model in laminar counterflow diffusion-flames, and provides novel insights for biomass combustion chemistry under oxy-fuel conditions.

Key words: anisole, PAH, OPAH, oxy-fuel combustion, counterflow flame

\section{Introduction}

One promising approach to achieve a carbon-neutral future energy supply is to utilize biomass with a low carbon footprint as alternative fuel [1]. A promising concept is biomass oxy-fuel combustion [2], which is burning biomass in a $\mathrm{CO}_{2} / \mathrm{O}_{2}$ instead of an air environment for easier and more efficient $\mathrm{CO}_{2}$ capture in the exhaust gas. Some pilot and middle scale examples are a $20 \mathrm{kWh}$ fluidized bed combustor [3] and a $1 \mathrm{MWh}$ furnace [4]. Investigating the biomass oxy-fuel combustion chemistry can support the development of future large-scale combustor-concept design and operation guidelines to achieve high efficiency and low emissions $[5,6]$.

The molecular structures of different biomasses are large and complicated, and depend on the source of biomass. Therefore, it is difficult to directly investigate combustion chemistry on a molecular level. Based on the abundant phenoxy and methyl functional groups in the molecular structure of lignin, anisole was proposed as the surrogate fuel to represent the combustion behavior of lignocellulosic biomass [7]. Hence, many studies have focused on the fundamentals of the combustion characteristics of anisole aiming for different measurement targets: shock tube (ST) [8-11] and rapid compression machine (RCM) [8] for the ignition 
delay time (IDT); Bunsen burner [12], heat flux burner [7], and combustion vessel [13] for the flame speed; flow reactor (FR) [14-20], jet stirred reactor (JSR) [7, 21-23], and premixed flames [24] for the speciation data. Table 1 summarizes the previous experimental work on anisole combustion/pyrolysis chemistry exploration. Based on the experimental data, many kinetic models $[7,19,23,25]$ were proposed to describe the combustion/pyrolysis chemistry of anisole.

Despite the wealth of previous studies, some important aspects involved in anisole combustion chemistry still remain in the dark. For example, there are no studies performed under oxy-fuel conditions, which is a promising biomass combustion mode. Furthermore, the aforementioned reactors are all premixed systems, which exclude the important diffusion process. We aim to fill this gap by exploring anisole combustion chemistry in diffusion flames under oxy-fuel conditions in this work.

Table 1: An overview of previous literature on the experimental measurements of anisole combustion/pyrolysis chemistry. Abbreviations: FR for flow reactor; JSR for jet stirred reactor; ST for shock tube; RCM for rapid compression machine; IDT for ignition delay time.

\begin{tabular}{|c|c|c|c|c|}
\hline Reactor & Target & Temperature $(\mathrm{K})$ & Pressure (bar) & Reference \\
\hline $\mathrm{FR}$ & Speciation & $793-1020$ & 1 & [14] \\
\hline FR & Speciation & $1000 \mathrm{~K}$ & 1 & [16] \\
\hline FR & Speciation & $873-1373$ & 1 & [15] \\
\hline FR & Speciation & $798-948$ & 1 & [17] \\
\hline FR & Speciation & $773-1573$ & 1 & [18] \\
\hline FR & Speciation & $850-1170$ & $0.04,1$ & [19] \\
\hline FR & Speciation & $573-923$ & 1 & [20] \\
\hline JSR & Speciation & $850-980$ & 1 & [22] \\
\hline JSR & Speciation & $673-1173$ & 1 & [23] \\
\hline JSR & Speciation & $770-1250$ & 1 & [7] \\
\hline JSR & Speciation & $700-1050$ & 1 & [21] \\
\hline ST & Speciation & $1000-1580$ & $0.4-0.9$ & {$[10]$} \\
\hline ST & Speciation & $565-1450$ & $1.3,2.9$ & [11] \\
\hline ST & IDT & $770-1600$ & $10,20,40$ & [9] \\
\hline ST/RCM & IDT & $850-1315$ & $10,20,40$ & [8] \\
\hline Bunsen burner & Flame speed & / & 1 & [12] \\
\hline
\end{tabular}




\begin{tabular}{lllll} 
Heat flux burner & Flame speed & $/$ & 1 & {$[7]$} \\
Combustion chamber & Flame speed & $/$ & $0.5-3$ & {$[13]$} \\
Premixed flame & Speciation & $/$ & 0.04 & {$[24]$} \\
\hline
\end{tabular}

In the present study, the combustion chemistry of anisole is investigated in two selected counterflow diffusion-flames under oxy-fuel conditions. Two measurement techniques, i.e., time-of-flight molecular-beam mass-spectrometry (ToF-MBMS) and gas-chromatography mass-spectrometry (GC-MS), were applied for chemical analysis. The latest kinetic model by Yuan et al. [19] was examined by the comparison of simulations and experiments. Model analysis and tentative kinetic model update indicated the potential to improve model predictions by updating the PAH (polycyclic aromatic hydrocarbons) and OPAH (oxygenated polycyclic aromatic hydrocarbons) chemistry. According to the best of our knowledge, this work provides the first comprehensive investigation of anisole combustion chemistry in diffusion flames or oxy-fuel conditions.

\section{Methodology}

\subsection{Counterflow burner}

Since the description of the atmospheric pressure counterflow burner setup has been illustrated in detail in previous literature [26-28], only a short description with key information and modifications is provided here. The opposed co-axial nozzles have an outer diameter of $20 \mathrm{~mm}$ and are $9 \mathrm{~mm}$ apart. The area contraction ratio in the converging nozzles is 9 . A nitrogen co-flow shields the flame from external perturbation. The flow field was calculated and validated in a previous study to ensure a 1-D flat stagnation plane in the counterflow flame [26]. A manual translation stage is used to adjust the position of diagnostic sampling along the centerline. 
To allow for liquid fuel investigation, a vaporizer from aDrop (model aSTEAM DV4K_E1.1) was added to the existing setup. From a pressurized tank, anisole is fed to the vaporizer by a Bronkhorst liquid mass flow controller (mini CORI-FLOW ${ }^{\mathrm{TM}}$ ML120V21, accuracy for liquid: $\pm 0.2 \%$ of the set mass flow rate). The vaporizer is heated to $200{ }^{\circ} \mathrm{C}$, and the gaseous fuel mixture is carried by the diluted methane/argon to the counterflow burner. Transfer lines from the vaporizer to the burner nozzle are heated to $160{ }^{\circ} \mathrm{C}$ to prevent condensation and thermal degradation of anisole (boiling point $153.8^{\circ} \mathrm{C}$ ).

Two different flame configurations under oxy-fuel conditions were investigated. In one case, $\mathrm{CO}_{2}$ replaced argon as diluent at the fuel side (referred to as $\mathrm{CO}_{2} \mathrm{~F}$-flame). In the other case, $\mathrm{CO}_{2}$ was introduced at the oxidizer side (referred to as $\mathrm{CO}_{2} \mathrm{O}$-flame). In both flames, the additional content of $\mathrm{CO}_{2}$ was $20 \%$ in molar fraction on the respective side to substitute argon. Further increase in $\mathrm{CO}_{2}$ share caused flame instability or even extinction. Except for the side where $\mathrm{CO}_{2}$ was added, all other conditions were identical in the $\mathrm{CO}_{2} \mathrm{~F}$-flame and $\mathrm{CO}_{2} \mathrm{O}$-flame. Due to the high boiling point of anisole, it is difficult to achieve a stable vapor flow at high concentrations. Therefore, the anisole mole fraction was set to be $5 \%$ in the fuel flow. $10 \%$ methane in mole fraction was added to the fuel flow as a dopant to keep the flame stable and additionally mimicked the practical co-firing process. The global strain rate [29] for both flames was set to $80 \mathrm{~s}^{-1}$ and the opposing flows were kept under momentum balance. The pressures of all the gas streams were slightly above the ambient pressure. The flame stability was continuously checked with recorded videos. The investigated conditions of the anisole counterflow flames are summarized in Table 2.

Table 2: Experimental conditions of the investigated anisole counterflow flames.

\begin{tabular}{|c|c|c|c|c|c|c|c|}
\hline \multirow[b]{2}{*}{ Flame } & \multicolumn{3}{|c|}{ Fuel side } & \multicolumn{3}{|c|}{ Oxidizer side } & \multirow{2}{*}{$\begin{array}{c}\text { strain } \\
\text { rate }\left(\mathrm{s}^{-1}\right)\end{array}$} \\
\hline & $\begin{array}{l}\text { Velocity } \\
(\mathrm{cm} / \mathrm{s})\end{array}$ & $\begin{array}{l}\text { Temp. } \\
\text { (K) }\end{array}$ & $\begin{array}{l}\text { Composition in } \\
\text { mole fraction }\end{array}$ & $\begin{array}{l}\text { Velocity } \\
(\mathrm{cm} / \mathrm{s})\end{array}$ & $\begin{array}{l}\text { Temp. } \\
\text { (K) }\end{array}$ & $\begin{array}{l}\text { Composition in } \\
\text { mole fraction }\end{array}$ & \\
\hline
\end{tabular}




\begin{tabular}{lccccccc}
\hline $\begin{array}{l}\mathrm{CO}_{2} \mathrm{~F}- \\
\text { flame }\end{array}$ & \multirow{2}{*}{18.0} & 433 & $\begin{array}{c}\text { anisole } 0.05, \\
\mathrm{CH}_{4} 0.1, \mathrm{Ar} \\
0.65, \mathrm{CO}_{2} \mathrm{O} .2\end{array}$ & 20.9 & 313 & $\mathrm{O}_{2} 0.5, \mathrm{Ar} 0.5$ & 80 \\
\hline $\begin{array}{l}\mathrm{CO}_{2} \mathrm{O}- \\
\text { flame }\end{array}$ & 18.0 & 433 & $\begin{array}{c}\text { anisole } 0.05, \\
\mathrm{CH}_{4} 0.1, \mathrm{Ar} \\
0.85\end{array}$ & 20.0 & 313 & $\begin{array}{c}\mathrm{O}_{2} 0.5, \mathrm{Ar} 0.3, \\
\mathrm{CO}_{2} 0.2\end{array}$ & 80 \\
\hline
\end{tabular}

\subsection{Time-of-flight molecular-beam mass-spectrometry}

ToF-MBMS was used in this work to detect and identify species by their different molecular weights. The detailed descriptions of the ToF-MBMS can be found in [26]. Here, only the key information about the ToF-MBMS is presented. The quartz nozzle with an orifice diameter of $30 \mu \mathrm{m}$ extracts the gas samples directly from the flames by a molecular beam generated from three stages of vacuum. The small orifice excludes the influence of neighboring zones on measurements along the centerline, which was investigated on the same setup by optical measurements in previous work [30]. The extracted molecules in the chamber are ionized by the electrons from thermionic emissions of a heated tungsten filament. The ionized molecules are then accelerated into the flight tube (molecules with different molecular weights are separated by their different flight time) and registered by the mass spectrometer detector for quantification. The mass resolution $(\mathrm{m} / \Delta \mathrm{m})$ of the ToF-MBMS is approximately 4000 .

Three energies $(12,14$, and $18 \mathrm{eV})$ were used for different species measurements in the counterflow flames. The energy selection criterion is to achieve high signals and minimize the fragmentation for each species. Two step sizes were used for flame position scans: $\mathrm{x}$ (distance from fuel nozzle) $=0-5 \mathrm{~mm}$ with a step size of $0.25 \mathrm{~mm}$ and $\mathrm{x}=5-8 \mathrm{~mm}$ with a step size of $0.5 \mathrm{~mm}$. Note that the species experimental data were shifted $1.0 \mathrm{~mm}$ away from the fuel nozzle to match with the simulation results. This is mainly due to the uncertainty in determining the zero-point position $(x=0 \mathrm{~mm})$. At this position, the fragile quartz nozzle almost touched the surface of the fuel nozzle, leaving a gap of approximately $1.0 \mathrm{~mm}$ due to the thickness of the quartz nozzle. The shifting distance was determined by the comparison between the 
measurements and simulated mole fraction profiles of the fuel, i.e., anisole and $\mathrm{CH}_{4}$. The shifting does not influence the following interpretation and analysis of the species data.

The calibration and data process procedure can be found in [26]. For reactants, the uncertainty is estimated to be $15 \%$ of the measured mole fraction. For other intermediates, with electron ionization cross sections available in the database [31], the uncertainty is a factor of 2 to 3 of the measured mole fraction.

\subsection{Gas chromatograph with mass spectrometry}

The gas sampling method developed in this work followed the approach established in the literature [32-36]. A silica sampling capillary (Molex) was used to directly extract gaseous samples from the flame. The left panel of Fig. 1 shows a photo of the sampling probe inserted into the flame. The outer diameter of the probe $(360 \mu \mathrm{m})$ was chosen according to Figura $e t$ al. [34] to minimize flame perturbation. The small inner diameter of $200 \mu \mathrm{m}$ allowed high spatial resolution and adequate sampling. The axial probe position was determined by the photos taken from a Canon EOS $1200 \mathrm{D}$ camera with a spatial accuracy of $0.2 \mathrm{~mm}$. Possible reactions in the probe were evaluated with chemical kinetic modeling by considering the residence time in the hot zone (the probe length inside the flame). The results indicated small changes in sample composition, which were within experimental uncertainty. Flame scans were performed at $\mathrm{x}=0-4 \mathrm{~mm}$. Sampling in the flame (position at $\mathrm{x}=4-5 \mathrm{~mm}$ ) was not feasible as the capillary bent at high temperatures. However, this limitation does not affect the results, as shown in the later sections, most of the interesting intermediates were produced and consumed within the investigated region.

The samples from the flame were stored in an automated gas sampling system. It consists of a gas measurement system (GMS, Teckso $\mathrm{GmbH}$ ) placed upon a mobile table, which allows for the collection of the samples and offline GC-MS analysis. The GMS stores gaseous samples 
in 16 sample loops at a constant temperature of $473 \mathrm{~K}$ to prevent condensation. Offline GCMS analysis was performed overnight by a computer-automated sequence. Potential sample alteration due to the storage time was tested by filling all the sample loops with a gaseous sample taken from a fixed flame position. The consecutive analysis showed constant species mole fraction for different storage times.

Sample analysis was performed by a gas chromatograph (GC, Agilent 6890N) equipped with a mass spectrometer (MSD, Agilent 5975C), thermal conductivity detector (TCD), and flame ionization detector (FID). The system is capable of separating, identifying, and quantifying the complex organic species in the mixtures. The GC-MS is composed of two channels as depicted in Fig. 2. The permanent gas channel (PGC) separates $\mathrm{O}_{2}, \mathrm{~N}_{2}, \mathrm{Ar}, \mathrm{CO}, \mathrm{CO}_{2}$, and $\mathrm{CH}_{4}$. Larger species are back-flushed. The PGC is connected to the TCD followed by the FID for quantification. Downstream of the TCD, a nickel-based catalytic converter (methanizer) hydrogenates $\mathrm{CO}$ and $\mathrm{CO}_{2}$ to $\mathrm{CH}_{4}$ and allows for their quantification in the FID. The hydrocarbon channel (HCC) separates $\mathrm{C}_{1}$ to $\mathrm{C}_{12}$ species. The flow is split to the MSD and merged with the PGC before the FID. Line restrictions in the $\mathrm{HCC}$ are selected to achieve similar species retention times in both FID and MSD, allowing for simultaneous identification by the MSD and quantification by the FID.

Both FID and TCD were calibrated for $\mathrm{CO}, \mathrm{CO}_{2}$, and $\mathrm{CH}_{4}$ by using a standard of a known gas mixture. The calibration of anisole was achieved through cold gas measurements at $\mathrm{x}=$ $0 \mathrm{~mm}$. All other species were quantified by using the effective carbon number (ECN) approach [37, 38]. Anisole served as the base species and the specific ECN of other species were obtained according to Faiola et al. [37]. An example of the chromatogram is presented in the right panel of Fig. 1. The error of directly calibrated species was estimated to be within $\pm 3 \%$, for small organic species $\left(\mathrm{C}_{2}-\mathrm{C}_{5}\right)$ within $\pm 20 \%$, and for aromatics, $\mathrm{PAH}$, and $\mathrm{OPAH}$ within $\pm 40 \%$ of the measured mole fraction. 

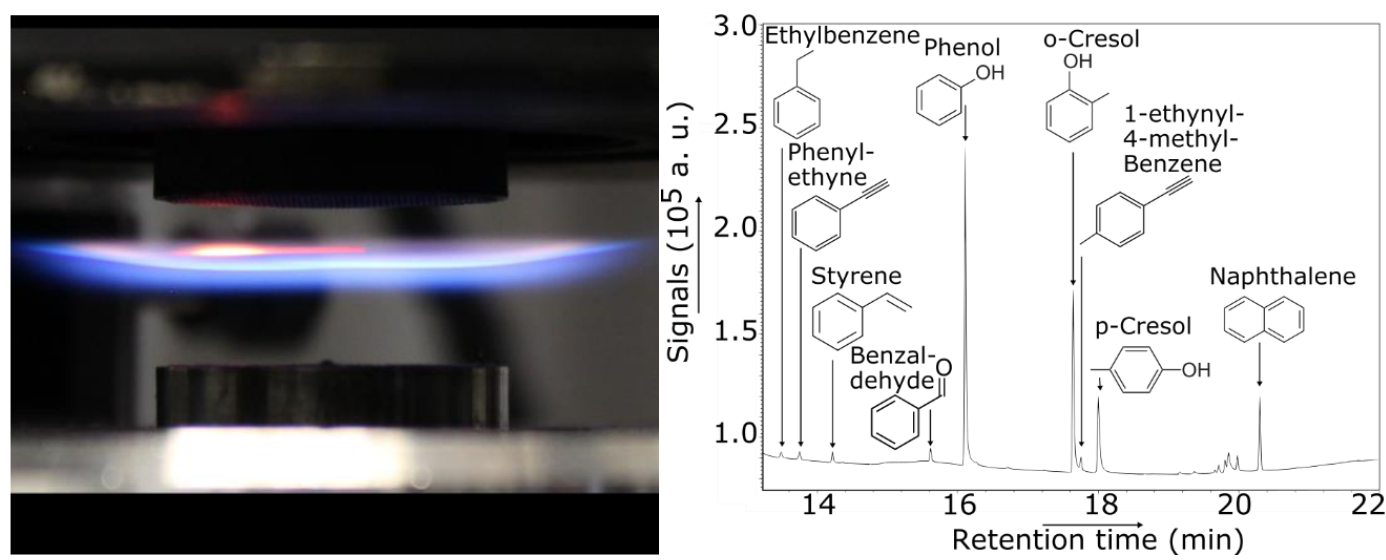

Figure 1: Left: Photo of the sampling probe for GMS and GC-MS in the anisole counterflow flame. Right: Example of the gas chromatograph from the samples in an anisole counterflow flame $\left(\mathrm{CO}_{2} \mathrm{~F}\right.$-flame, $\left.\mathrm{x}=2.5 \mathrm{~mm}\right)$.

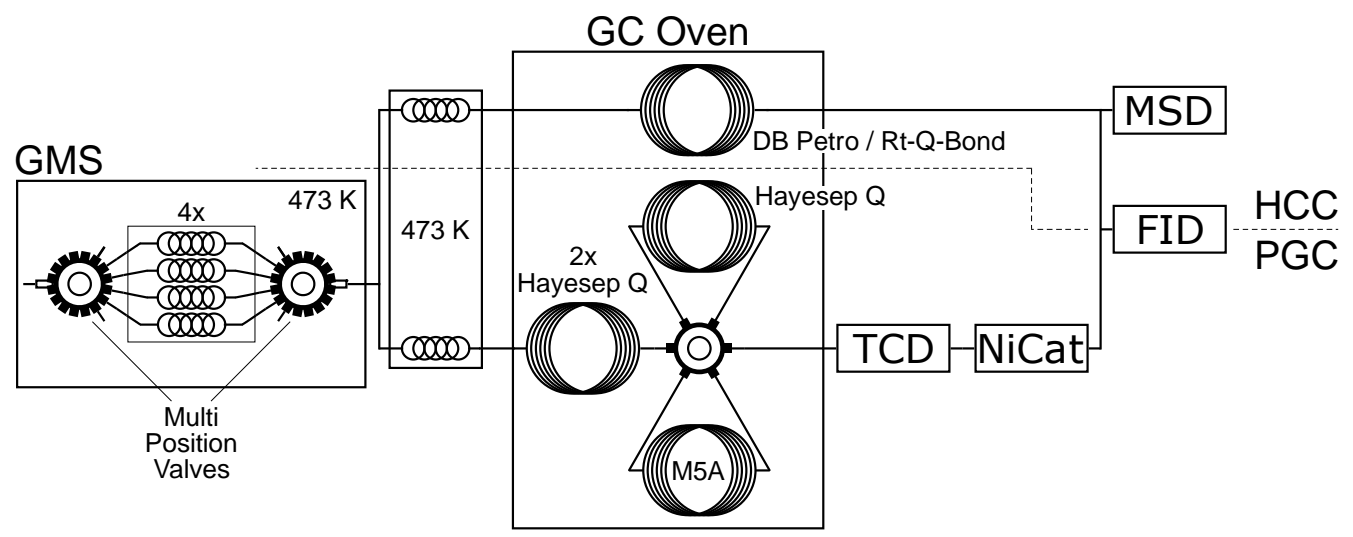

Figure 2: Schematics of GMS and GC-MS.

\subsection{Kinetic modelling}

The kinetic model of anisole used in this work was taken from Yuan et al. [19] with 432 species and 2563 reactions. The reasons for choosing this model are as follows: (a) it is the latest model from the literature that was comprehensively validated; (b) compared to another model from Lawrence Livermore National Laboratory [7], the model size is moderate to keep the computational cost acceptable. 
Numerical simulations were performed with the Chemkin software [39] by using the opposed flow diffusion flame code with the mixture-average transport model. The inputs of the two investigated flames can be found in Table 2. Rate of production analysis and sensitivity analysis tools were used to reveal the dominant production/consumption pathways and sensitive reactions for the species of interest.

\section{Results and discussion}

In this section, the comparison of species mole fraction profiles from the experiments and simulations of the $\mathrm{CO}_{2} \mathrm{~F}$-flame and the $\mathrm{CO}_{2} \mathrm{O}$-flame are presented. In all of the figures with species mole fraction profiles (Fig. 3, 6-10, 12-13), the red crosses mark the data from ToFMBMS measurements; the blue circles from GC-MS measurements with the Rt-Q-bond column; the green triangles from GC-MS measurements with the DB-Petro column; and the solid black lines represent the numerical simulations by using the kinetic model from Yuan et al. [19]. Table S1 in Supplementary Material-1 lists all detected species of the different measurement techniques. Supplementary Material-2 presents the experimental data acquired in this work.

\subsection{Reactants and main products}

Figure 3 shows the mole fraction profiles of the reactants (anisole, $\mathrm{CH}_{4}$, and $\mathrm{O}_{2}$ ) and the main products $\left(\mathrm{H}_{2} \mathrm{O}, \mathrm{CO}\right.$, and $\left.\mathrm{CO}_{2}\right)$ in the $\mathrm{CO}_{2} \mathrm{~F}$-flame. The three datasets show good agreements for anisole (Fig. 3a), $\mathrm{CH}_{4}$ (Fig. 3b), $\mathrm{CO}$ (Fig. 3e), and $\mathrm{CO}_{2}$ (Fig. 3f). The good agreement of the measurements by different experimental methods provides a cross-validation of the techniques. For $\mathrm{CH}_{4}$ (Fig. 3a), $\mathrm{O}_{2}$ (Fig. 3c), and $\mathrm{H}_{2} \mathrm{O}$ (Fig. 3d), the mole fraction profiles from the experiments match well with the kinetic model simulations. The measurements performed with the ToF-MBMS in Fig. 3a are the summation of all $\mathrm{C}_{7} \mathrm{H}_{8} \mathrm{O}$ isomers, since the ToF-MBMS cannot separate anisole and its isomers, o- and p-cresol, due to their close 
ionization energies [19]. This is likely the main reason for the deviations between the ToFMBMS and the GC-MS measurements. Especially at $\mathrm{x}=3-4 \mathrm{~mm}$, the isomer contributions may lead to the apparently reduced consumption slope of the anisole profile. The GC-MS is capable of separating the isomers, which is why the measurements agree better with numerical simulations in $\mathrm{CO}_{2} \mathrm{~F}$-flame.

The mole fraction profiles of $\mathrm{CO}_{2}$ and $\mathrm{CO}$ are not well captured by the simulation in the rich region of the flame (Fig. 3e and Fig. 3f). The mole fraction of $\mathrm{CO}$ is overpredicted at $\mathrm{x}=4 \mathrm{~mm}$ by the model (Fig. 3f). Meanwhile, the calculated $\mathrm{CO}_{2}$ mole fraction profile shows consumption at $\mathrm{x}=2-4 \mathrm{~mm}$ and production at $\mathrm{x}=4-5 \mathrm{~mm}$ (Fig. 3e). However, this course is not displayed in the experimental measurements, which show a monotonic decrease of the $\mathrm{CO}_{2}$ mole fraction profile at $\mathrm{x}=2-5 \mathrm{~mm}$. This suggests that the mismatch between the simulations and experiments of $\mathrm{CO}$ and $\mathrm{CO}_{2}$ may root in the inaccurate conversion ratio between $\mathrm{CO}$ and $\mathrm{CO}_{2}$.

To reveal the responsible reactions, model analyses were performed for $\mathrm{CO}$ and $\mathrm{CO}_{2}$ in the $\mathrm{CO}_{2} \mathrm{~F}$-flame. Figure 4 lists the top five production/consumption reactions obtained by a rate of production analysis. The dominant production pathways of $\mathrm{CO}$ are $\mathrm{HCO}+\mathrm{M} \Leftrightarrow \mathrm{H}+\mathrm{CO}+$ $\mathrm{M}, \mathrm{CO}+\mathrm{OH} \Leftrightarrow \mathrm{CO}_{2}+\mathrm{H}$, and $\mathrm{HCCO}+\mathrm{H} \Leftrightarrow \mathrm{CH}_{2}(\mathrm{~S})+\mathrm{CO}$ at $\mathrm{x}=3.8 \mathrm{~mm}$. At $\mathrm{x}=3.1 \mathrm{~mm}$, $\mathrm{CO}$ is also produced at very rich conditions by the dissociation reaction of the phenoxy radical $\mathrm{A} 1 \mathrm{O} \Leftrightarrow \mathrm{C}_{5} \mathrm{H}_{5}+\mathrm{CO}$, as expected in the pyrolysis-dominant region [40]. At $\mathrm{x}=3.8 \mathrm{~mm}$, the main consumption reactions of $\mathrm{CO}_{2}$ are $\mathrm{CO}+\mathrm{OH} \Leftrightarrow \mathrm{CO}_{2}+\mathrm{H}$, and $\mathrm{CH}_{2}(\mathrm{~S})+\mathrm{CO}_{2} \Leftrightarrow \mathrm{CH}_{2} \mathrm{O}$ + CO. The sensitivity analysis at this location (see Fig. 5) revealed the top ten sensitive reactions to the species formation. A positive value denotes that the reaction promotes species production, and a negative value denotes that the reaction suppresses species formation. Besides $\mathrm{CO}+\mathrm{OH} \Leftrightarrow \mathrm{CO}_{2}+\mathrm{H}$ (marked in red in Fig. 5), $\mathrm{CH}_{3}+\mathrm{C}_{5} \mathrm{H}_{5}(+\mathrm{M}) \Leftrightarrow=\mathrm{H}+\mathrm{C}_{5} \mathrm{H}_{4} \mathrm{CH}_{3}$ $(+\mathrm{M})$, and $\mathrm{C}_{2} \mathrm{H}_{2}+\mathrm{O} \Leftrightarrow=\mathrm{HCCO}+\mathrm{H}$ (marked in green in Fig. 5) are among the top sensitive 
reactions to promote $\mathrm{CO}$ production and $\mathrm{CO}_{2}$ consumption, and reactions from $\mathrm{PAH}$ chemistry have some minor influence (marked in blue in Fig. 5). Here, the reaction $\mathrm{CO}+\mathrm{OH} \Leftrightarrow \mathrm{CO}_{2}$ $+\mathrm{H}$, one of the most important reactions in combustion, has been well studied over decades, which is why the rate coefficients are considered to be reliable. The rate coefficients of reaction $\mathrm{CH}_{3}+\mathrm{C}_{5} \mathrm{H}_{5}(+\mathrm{M})<=>\mathrm{H}+\mathrm{C}_{5} \mathrm{H}_{4} \mathrm{CH}_{3}(+\mathrm{M})$ are from a recent quantum chemistry calculation study by Wang et al. [41]. But the rate coefficients of reaction $\mathrm{C}_{2} \mathrm{H}_{2}+\mathrm{O} \Leftrightarrow \mathrm{HCCO}+\mathrm{H}$ are from the old GRIMech 3.0 model [42]. The base chemistry may need to be replaced by more recent $\mathrm{C}_{1}-\mathrm{C}_{4}$ core models, e.g., by the ArmacoMech 3.0 model [43] or the NUIGMech 1.1 model [44]. Another possible reason is the overprediction of the $\mathrm{H}$ radical in the radical pool by the kinetic model. With the existence of a high amount of $\mathrm{CO}_{2}$, the extra $\mathrm{H}$ radical at $\mathrm{x}=$ $3.8 \mathrm{~mm}$ may shift the chemical equilibrium of $\mathrm{CO}+\mathrm{OH} \Leftrightarrow \mathrm{CO}_{2}+\mathrm{H}$ to the reactant side and result in higher production of $\mathrm{CO}$ and higher consumption of $\mathrm{CO}_{2}$. This possibility may be supported by the overpredictions of hydrogen as shown in the following section.

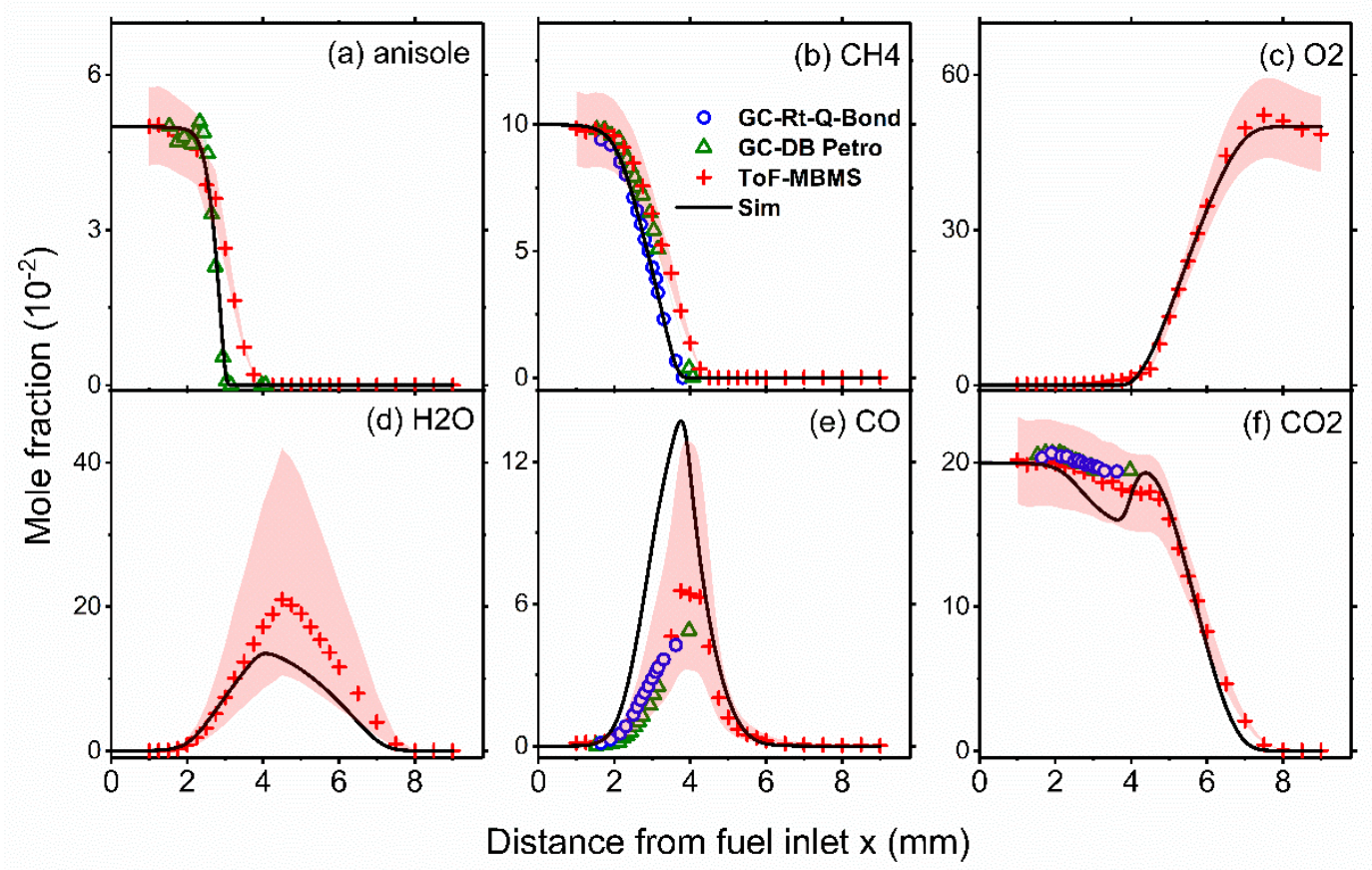

Figure 3: Mole fraction profiles of the reactants (anisole, $\mathrm{CH}_{4}$, and $\left.\mathrm{O}_{2}\right)$ and main products $\left(\mathrm{H}_{2} \mathrm{O}\right.$, $\mathrm{CO}$, and $\mathrm{CO}_{2}$ ) in the $\mathrm{CO}_{2} \mathrm{~F}-$ flame. Legends: red crosses from ToF-MBMS; blue circles from 
GC-MS with the Rt-Q-Bond column; green triangles from GC-MS with the DB-Petro column; and solid black lines from the kinetic model simulations. Shaded areas with different colors indicate the measurement uncertainty of the respective techniques. The uncertainty of GC-MS measurements is too small to be seen.

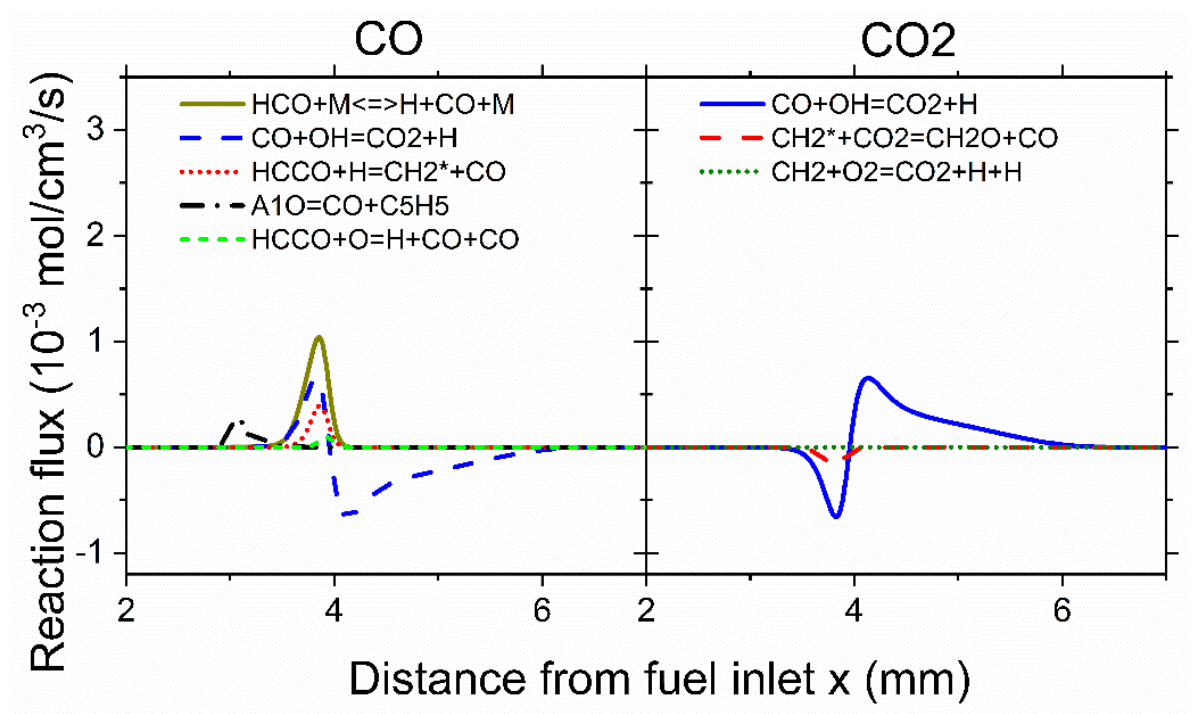

Figure 4: Rate of production analysis of $\mathrm{CO}$ and $\mathrm{CO}_{2}$ in the $\mathrm{CO}_{2} \mathrm{~F}$-flame. 


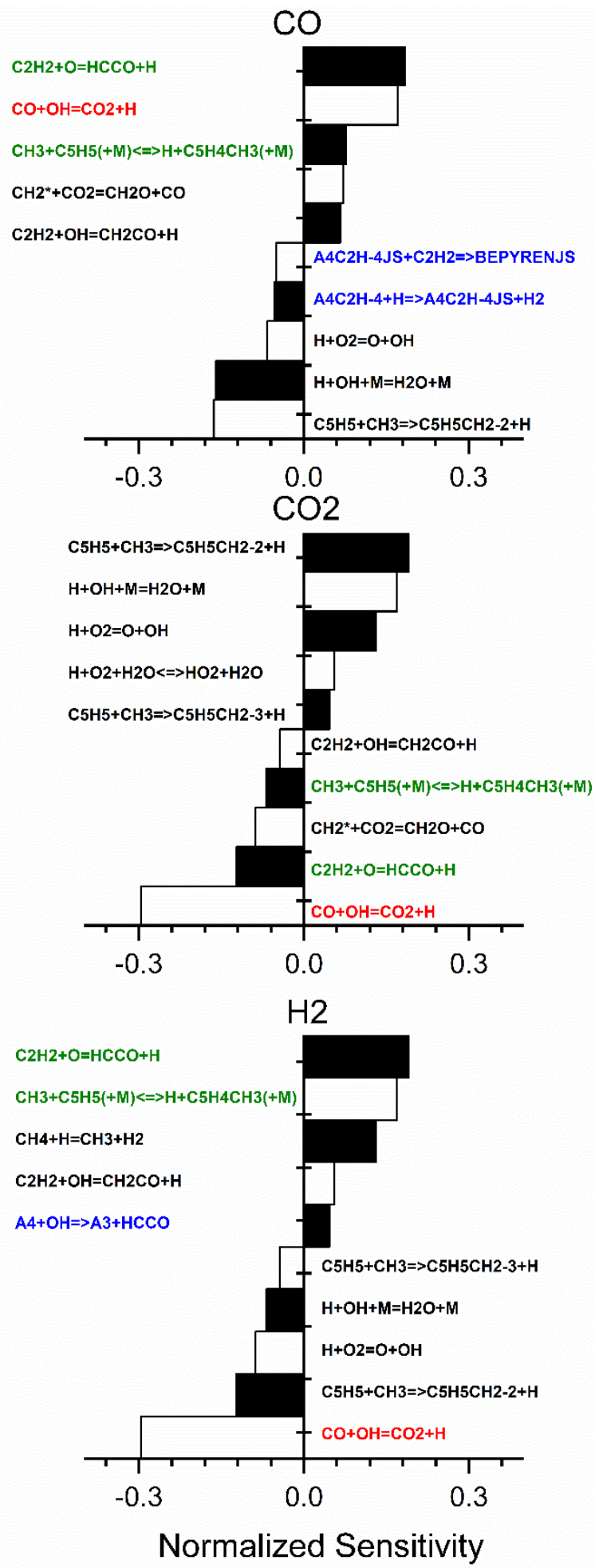

Figure 5: Sensitivity analysis of $\mathrm{CO}, \mathrm{CO}_{2}$, and $\mathrm{H}_{2}$ in the $\mathrm{CO}_{2} \mathrm{~F}$-flame at $\mathrm{x}=3.8 \mathrm{~mm}$.

The mole fraction profiles of the reactants and the main products for the $\mathrm{CO}_{2} \mathrm{O}$-flame are shown in Fig. 6. The experimental results of the different measurement techniques again match well. Similar to the $\mathrm{CO}_{2} \mathrm{~F}-$ flame, the mole fraction profiles of anisole, $\mathrm{CH}_{4}, \mathrm{O}_{2}$, and $\mathrm{H}_{2} \mathrm{O}$ agree 
well (see Fig. 6) between the simulations and experiments within the experimental uncertainty. However, discrepancies appear again when comparing the simulations and experiments for CO and $\mathrm{CO}_{2}$ mole fraction profiles. The mole fraction profiles of $\mathrm{CO}$ are over-predicted at $\mathrm{x}=4 \mathrm{~mm}$, and those of $\mathrm{CO}_{2}$ are over-predicted at $\mathrm{x}=5.4 \mathrm{~mm}$. According to the rate of production analysis in Fig. S1 in Supplementary Material-1, the main production and consumption reactions in the $\mathrm{CO}_{2} \mathrm{O}$-flame are similar to those identified for the $\mathrm{CO}_{2} \mathrm{~F}$-flame. The faulty radical pool caused by the inaccurate rate coefficients of the reactions in $\mathrm{C}_{1}-\mathrm{C}_{4}$ chemistry may be the cause. The sensitivity analyses for $\mathrm{CO}$ at $\mathrm{x}=4.0 \mathrm{~mm}$ and $\mathrm{CO}_{2}$ at $\mathrm{x}=5.5 \mathrm{~mm}$ are shown in Fig. S2 in Supplementary Material-1. Some of the top ten sensitive reactions are from the PAH chemistry indicating that the inaccurate PAH chemistry may be another cause for $\mathrm{CO} / \mathrm{CO}_{2}$ overprediction.
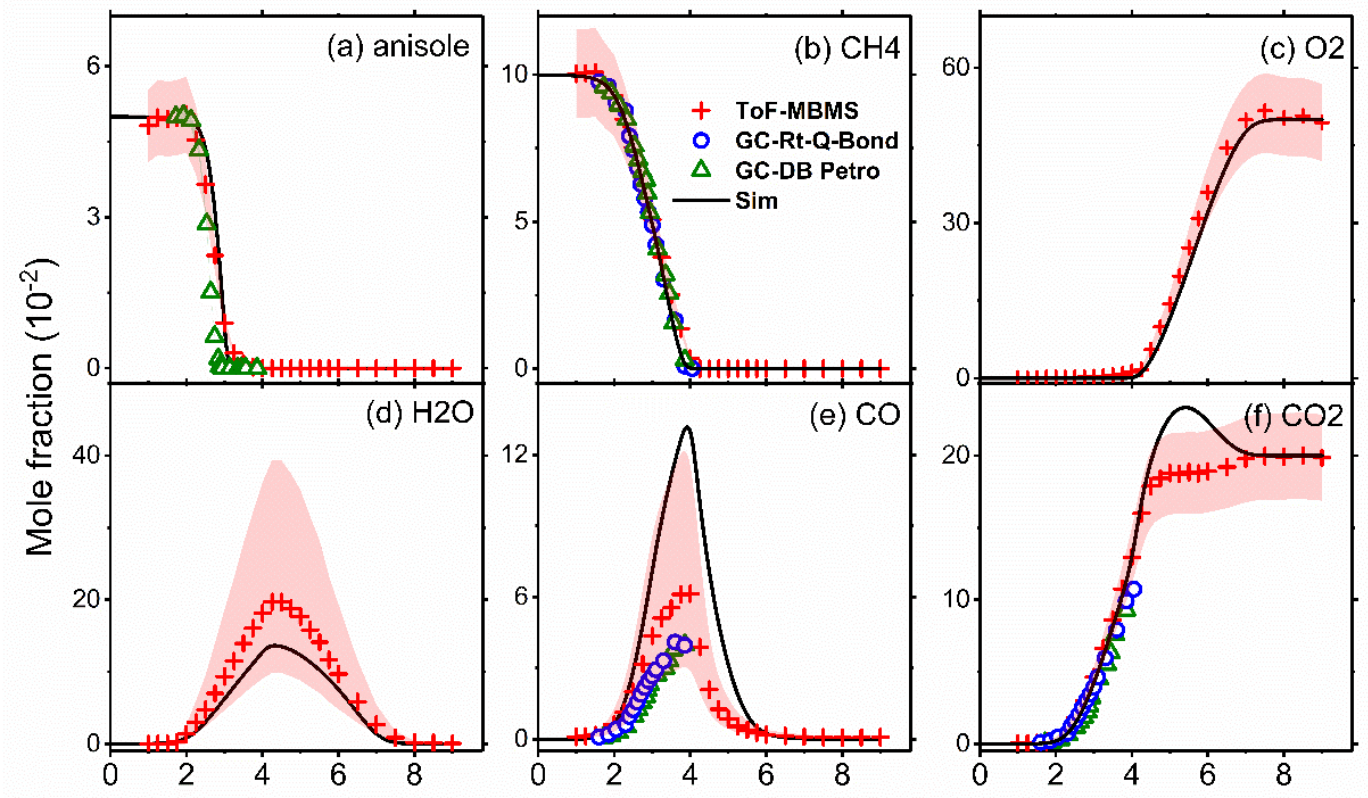

Distance from fuel inlet $x(\mathrm{~mm})$

Figure 6: Mole fraction profiles of the reactants (anisole, $\mathrm{CH}_{4}$, and $\mathrm{O}_{2}$ ) and main products $\left(\mathrm{H}_{2} \mathrm{O}\right.$, $\mathrm{CO}$, and $\left.\mathrm{CO}_{2}\right)$ in the $\mathrm{CO}_{2} \mathrm{O}$-flame. Legends: red crosses from ToF-MBMS; blue circles from GC-MS with the Rt-Q-Bond column; green triangles from GC-MS with the DB-Petro column; and solid black lines from the kinetic model simulations. Shaded areas with different colors 
indicate the measurement uncertainty of the respective techniques. The uncertainty of GC-MS measurements is too small to be seen.

\subsection{Small intermediates}

The mole fraction profiles of small intermediates in the $\mathrm{CO}_{2} \mathrm{~F}$-flame are presented in Fig. 7, and for the $\mathrm{CO}_{2} \mathrm{O}$-flame in Fig. 8. Twelve small intermediates, namely hydrogen $\left(\mathrm{H}_{2}\right)$, formaldehyde $\left(\mathrm{CH}_{2} \mathrm{O}\right)$, acetylene $\left(\mathrm{C}_{2} \mathrm{H}_{2}\right)$, ethylene $\left(\mathrm{C}_{2} \mathrm{H}_{4}\right)$, ethane $\left(\mathrm{C}_{2} \mathrm{H}_{6}\right)$, allene, propyne, propene $\left(\mathrm{C}_{3} \mathrm{H}_{6}\right)$, diacetylene $\left(\mathrm{C}_{4} \mathrm{H}_{2}\right)$, vinyl-acetylene, 1,3-butadiene, and 1,3-cyclopentadiene $\left(\mathrm{C}_{5} \mathrm{H}_{6}\right)$ were selected since they are important intermediates with notable concentrations in anisole combustion chemistry [7, 19, 23].

At first, the results of the GC-MS and ToF-MBMS are compared. From the comparison of the experimental datasets, the mole fraction profiles of most of the species, i.e., $\mathrm{C}_{2} \mathrm{H}_{4}$ (Fig. 7a), $\mathrm{C}_{3} \mathrm{H}_{6}$ (Fig. 7g), $\mathrm{C}_{4} \mathrm{H}_{2}$ (Fig. 7j), vinylacetylene (Fig. 7h), and $\mathrm{C}_{5} \mathrm{H}_{6}$ (Fig. 7e) match well with each other within the experimental uncertainty in both $\mathrm{CO}_{2} \mathrm{~F}$-flame and $\mathrm{CO}_{2} \mathrm{O}$-flame. However, a significant discrepancy exists for the $\mathrm{C}_{2} \mathrm{H}_{2}$ mole fraction profiles (Fig. 7b). The GC-MS data show higher values than the ToF-MBMS data in the $\mathrm{CO}_{2} \mathrm{~F}$-flame. In the $\mathrm{CO}_{2} \mathrm{O}$-flame, the discrepancy is smaller (see Fig. 8b). The mismatch of the experimental data may be rooted in the large uncertainty of the ToF-MBMS. The good match between GC-MS data and simulation results may support this explanation.

Now we compare the experimental data with the simulation results. The kinetic model simulations predict the mole fraction profiles of $\mathrm{C}_{2} \mathrm{H}_{2}, \mathrm{C}_{5} \mathrm{H}_{6}$, allene, propyne, $\mathrm{C}_{3} \mathrm{H}_{6}$, and vinylacetylene in both $\mathrm{CO}_{2}$ F-flame and $\mathrm{CO}_{2} \mathrm{O}$-flame well (Fig. 7 and Fig. 8). However, the mole fraction profiles of $\mathrm{C}_{2} \mathrm{H}_{4}, \mathrm{C}_{2} \mathrm{H}_{6}, \mathrm{CH}_{2} \mathrm{O}$, and 1,3-butadiene are under-predicted, and the mole fraction profiles of $\mathrm{H}_{2}$ and $\mathrm{C}_{4} \mathrm{H}_{2}$ are over-predicted in both $\mathrm{CO}_{2} \mathrm{~F}$-flame and $\mathrm{CO}_{2} \mathrm{O}$-flame. In the premixed systems $[7,23,24]$, the deviations of the $\mathrm{H}_{2}$ mole fractions between the 
experiments and kinetic model simulations are smaller. The sensitivity analysis for $\mathrm{H}_{2}$ (see Fig. 5) at $\mathrm{x}=3.8 \mathrm{~mm}$ indicates the responsible reactions are $\mathrm{C}_{2} \mathrm{H}_{2}+\mathrm{O} \Leftrightarrow \mathrm{HCCO}+\mathrm{H}$ and $\mathrm{C}_{5} \mathrm{H}_{5}(+\mathrm{M})<=>\mathrm{H}+\mathrm{C}_{5} \mathrm{H}_{4} \mathrm{CH}_{3}(+\mathrm{M})$. These reactions also appear in the sensitivity analyses of $\mathrm{CO}$ and $\mathrm{CO}_{2}$. Therefore, the influence of the rate coefficients of these two reactions on the predictions of $\mathrm{CO}, \mathrm{CO}_{2}$, and $\mathrm{H}_{2}$ might be higher in the diffusion systems compared to the premixed systems.

The comparison of other species predictions with experiments is consistent with the premixed systems $[7,23,24]$. From the kinetic model validation in previous literature [19], the mole fraction profiles of $\mathrm{C}_{2} \mathrm{H}_{4}$ were under-predicted in JSR oxidation [7, 23]; $\mathrm{C}_{2} \mathrm{H}_{6}$ was underpredicted in JSR oxidation [7, 23] and for a rich premixed flame [24]; and $\mathrm{CH}_{2} \mathrm{O}$ was underpredicted in FR pyrolysis [19]. The similar species prediction trends suggest that the species formation and consumption pathways need further investigation. 


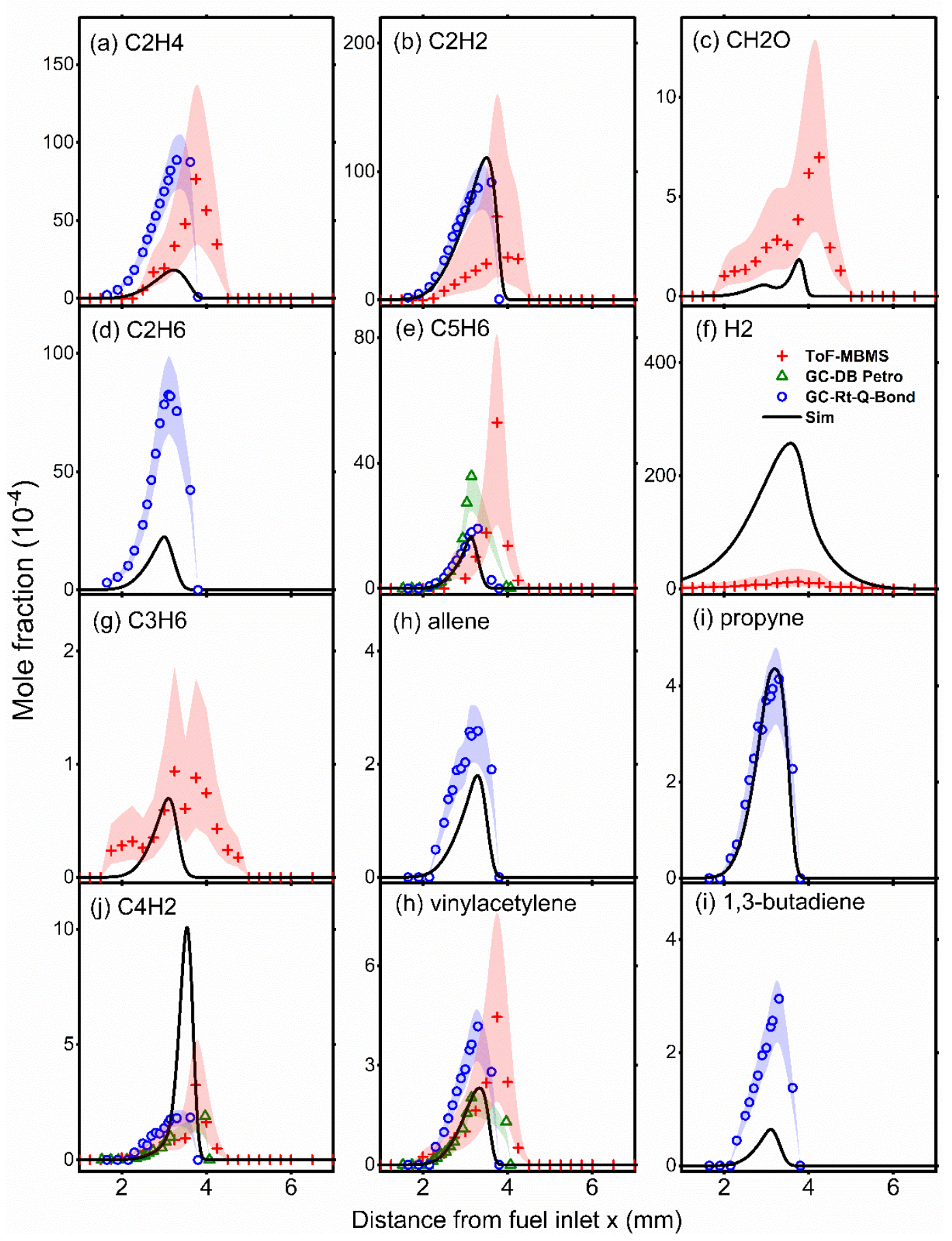

Figure 7: Mole fraction profiles of small intermediates in the $\mathrm{CO}_{2} \mathrm{~F}$-flame. Legends: red crosses from ToF-MBMS; blue circles from GC-MS with the Rt-Q-Bond column; green triangles from GC-MS with the DB-Petro column; and solid black lines from the kinetic model simulations. Shaded areas with different colors indicate the measurement uncertainty of the respective techniques. 


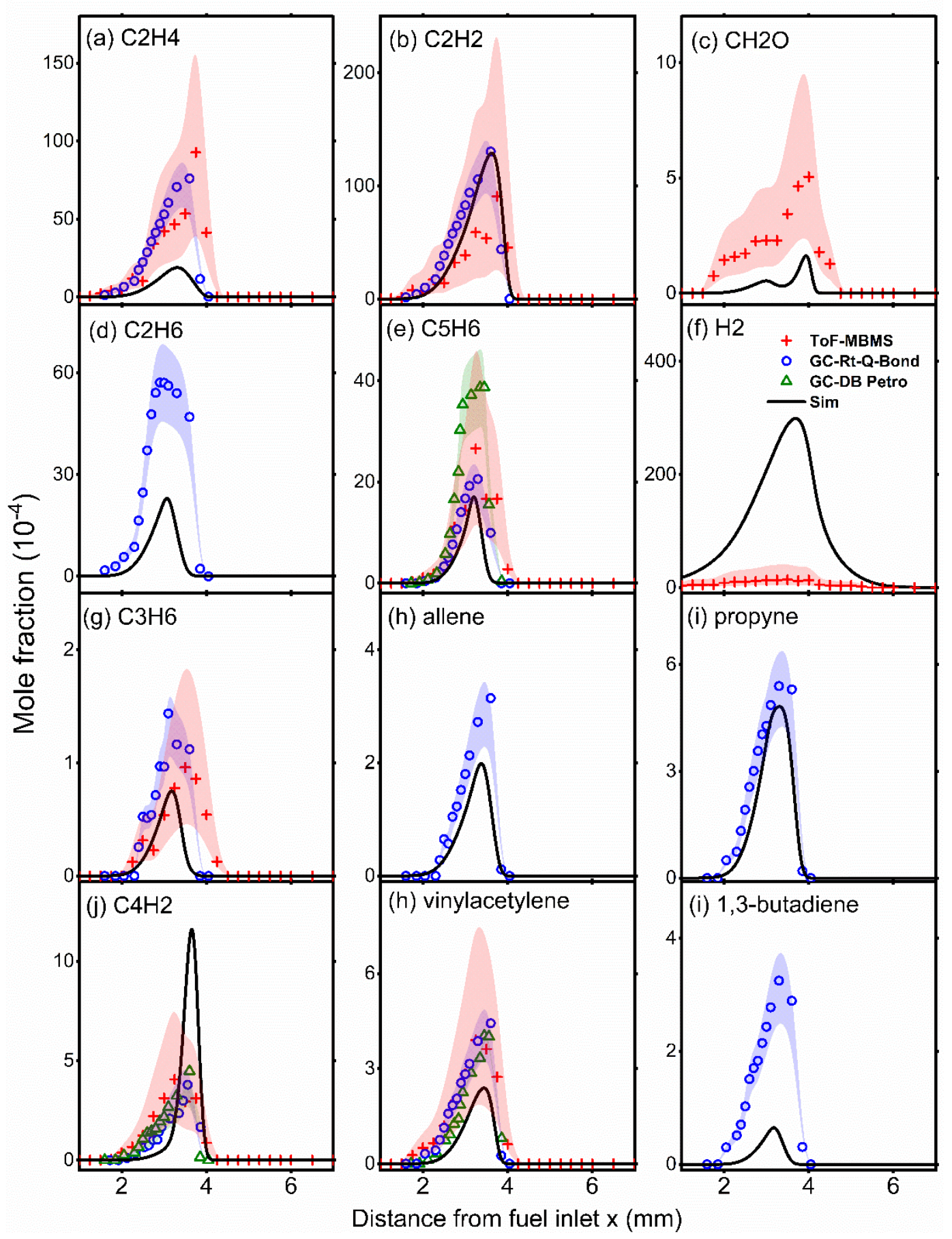

Figure 8: Mole fraction profiles of small intermediates in the $\mathrm{CO}_{2} \mathrm{O}$-flame. Legends: red crosses from ToF-MBMS; blue circles from GC-MS with the Rt-Q-Bond column; green triangles from GC-MS with the DB-Petro column; and solid black lines from the kinetic model simulations. Shaded areas with different colors indicate the measurement uncertainty of the respective techniques. 


\subsection{Aromatic species}

Figures 9 and 10 present the mole fraction profiles of aromatic species with up to three aromatic rings, i.e., benzene (Fig. 9a), 5-methyl-1,3-cyclopentadiene (Fig. 9b), toluene (Fig. 9c), phenylacetylene (Fig. 9d), styrene (Fig. 9e), ethylbenzene (Fig. 9f), 1-ethynyl-4methylbenzene (Fig. 9g), naphthalene (Fig. 9h), and acenaphthylene (Fig. 9i). Note that $\mathrm{C}_{9} \mathrm{H}_{8}$ was identified by the GC-MS as 1-ethynyl-4-methylbenzene in this work (see Fig. 2), but in the previous literature, it is reported as indene in the JSR oxidation [7] and FR pyrolysis [19].

The mole fraction profiles of benzene (Fig. 9a) and toluene (Fig. 9c) match well for the GCMS and ToF-MBMS measurements. For other species shown in Fig. 9, the low signals at low electron energies and high fragmentation potential at higher electron energies lead to increased uncertainty for the ToF-MBMS measurements, which is why the ToF-MBMS data are not shown here. In both $\mathrm{CO}_{2} \mathrm{~F}$-flame and $\mathrm{CO}_{2} \mathrm{O}$-flame, the mole fraction profiles of benzene (Fig. 9a and Fig. 10a), 5-methyl-1,3-cyclopentadiene (Fig. 9b and Fig. 10b), toluene (Fig. 9c and Fig. 10c), and ethylbenzene (Fig. 9f and Fig. 10f) agree well between the experiments and kinetic model simulations. However, the mole fraction profiles of other interesting aromatic hydrocarbons including phenylacetylene, styrene, ethylbenzene, naphthalene, and acenaphthylene are over-predicted by the kinetic model simulations. Interestingly, the overpredictions of PAH molecules are opposite to the premixed systems [19]. The under-prediction of naphthalene was found in the JSR oxidation [7]. Phenylacetylene was under-predicted in rich premixed flames [24], which suggests the PAH chemistry might be different between the premixed and diffusion systems. A similar difference has been illustrated for the soot formation in premixed and diffusion flames [45]. In section 3.5, the tentative kinetic model update for PAH and OPAH chemistry successfully narrows down the discrepancies, indicating a potential direction to improve the PAH predictions. 


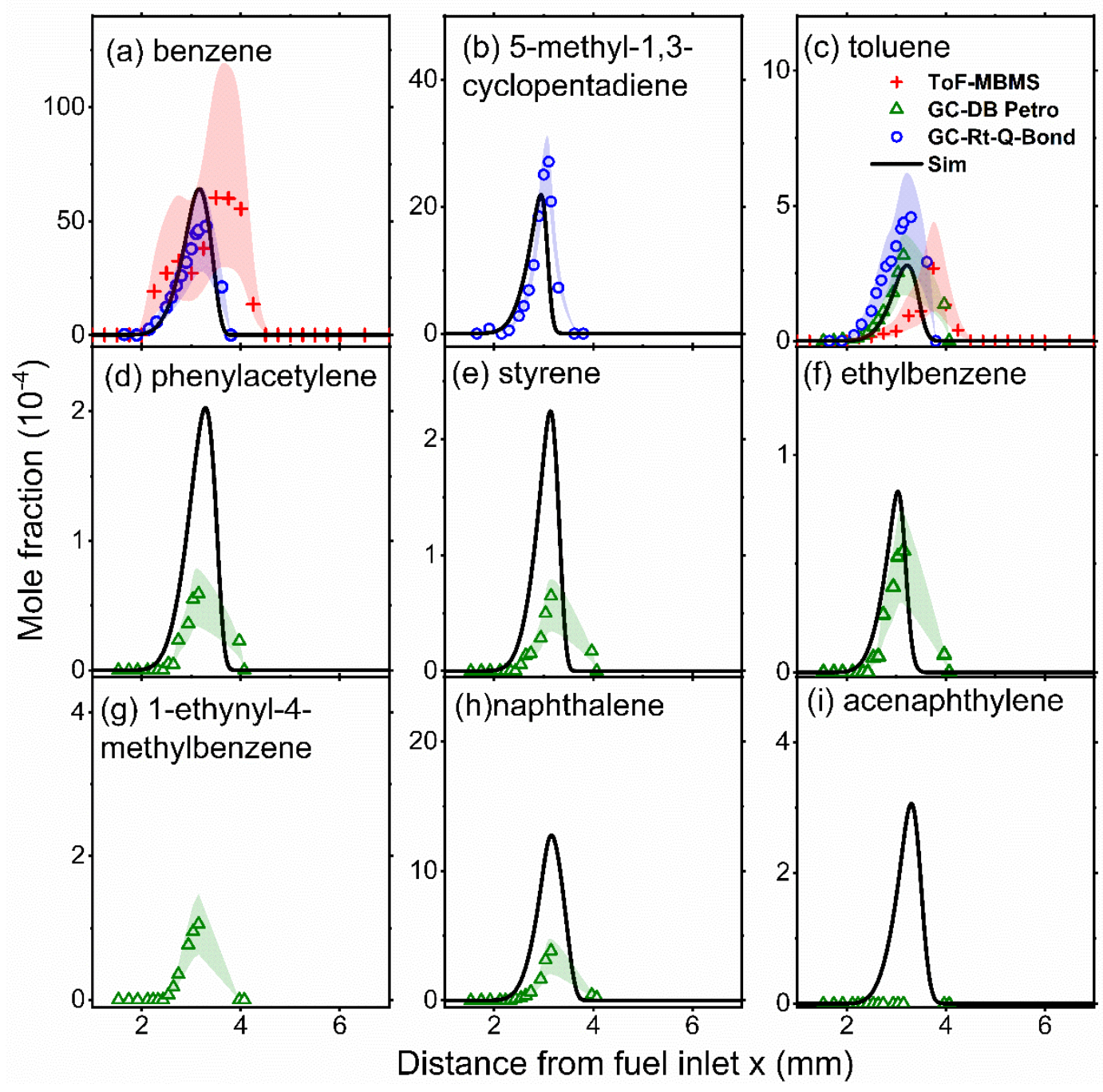

Figure 9: Mole fraction profiles of aromatic hydrocarbons and $\mathrm{PAH}$ in the $\mathrm{CO}_{2} \mathrm{~F}$-flame. Legends: red crosses from ToF-MBMS; blue circles from GC-MS with the Rt-Q-Bond column; green triangles from GC-MS with the DB-Petro column; and solid black lines from the kinetic model simulations. Shaded areas with different colors indicate the measurement uncertainty of the respective techniques. 


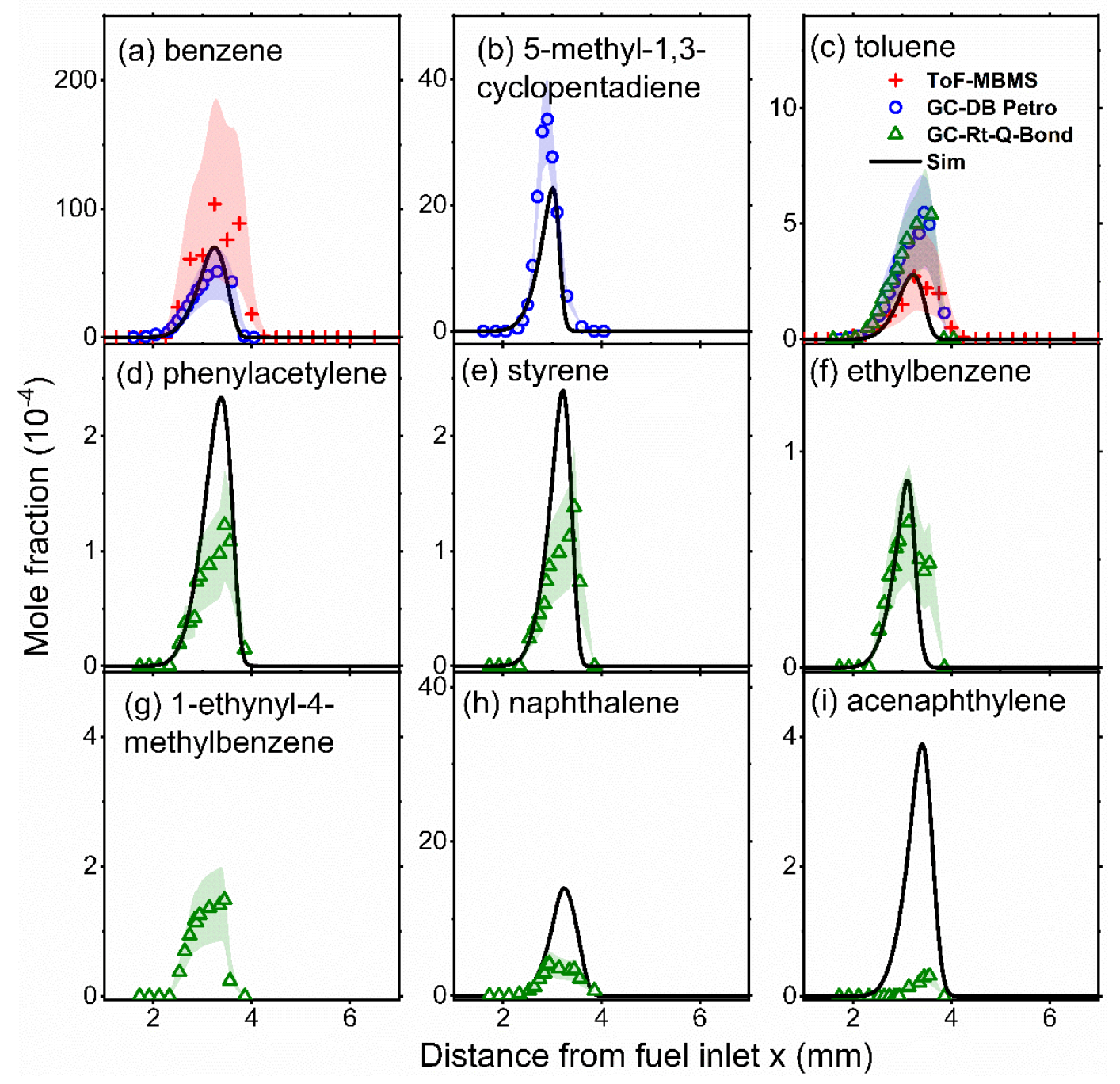

Figure 10: Mole fraction profiles of aromatic hydrocarbons and $\mathrm{PAH}$ in the $\mathrm{CO}_{2} \mathrm{O}$-flame. Legends: red crosses from ToF-MBMS; blue circles from GC-MS with the Rt-Q-Bond column; green triangles from GC-MS with the DB-Petro column; and solid black lines from the kinetic model simulations. Shaded areas with different colors indicate the measurement uncertainty of the respective techniques.

To further reveal the responsible reactions for the general over-predictions by the kinetic model, a rate of production analysis was performed for phenylacetylene, styrene, naphthalene, and acenaphthylene. The results for the $\mathrm{CO}_{2} \mathrm{~F}$-flame are shown in Fig. 11. For the $\mathrm{CO}_{2} \mathrm{O}$-flame, the results are shown in Fig. S3 in Supplementary Material-1. The identified key reaction pathways are similar between the $\mathrm{CO}_{2} \mathrm{~F}$-flame and $\mathrm{CO}_{2} \mathrm{O}$-flame, so the following discussion 
focuses on the $\mathrm{CO}_{2} \mathrm{~F}$-flame. The rate coefficients of the most dominant production pathway for phenylacetylene, A1- $+\mathrm{C}_{2} \mathrm{H}_{2} \Leftrightarrow \mathrm{A}_{1} \mathrm{C}_{2} \mathrm{H}$, were estimated by analogy [19], which can be updated by the quantum chemistry calculation results in our recent work [46]. For the dominant

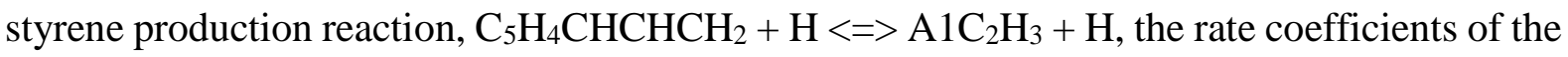
ring enlargement reaction were estimated by analogy in the model [19], which could also be updated to the recent quantum chemistry calculations by Mao et al. [47]. The recombination of cyclopentadienyl radicals is the dominant production pathway for the formation of naphthalene. The rate coefficients were adopted from Mebel et al. [48], which could be updated to the latest ones from $[49,50]$. For acenaphthylene, the key reactions are A2R5- $+\mathrm{H}(+\mathrm{M})<=>$ A2R5 $(+\mathrm{M})$ and $\mathrm{C}_{9} \mathrm{H}_{7}+\mathrm{CH}_{3}<=>\mathrm{A} 2 \mathrm{R} 5+\mathrm{H}_{2}$. The former rate coefficients were estimated by analogy to the hydrogen-abstraction-carbon-addition (HACA) mechanism [51], and the latter one is from Blanquart et al. [52]. Updating the PAH chemistry in future model development may improve the predictions of these aromatics and PAH molecules. The tentative model update in section 3.5 shows an example and the potential to improve PAH predictions. 


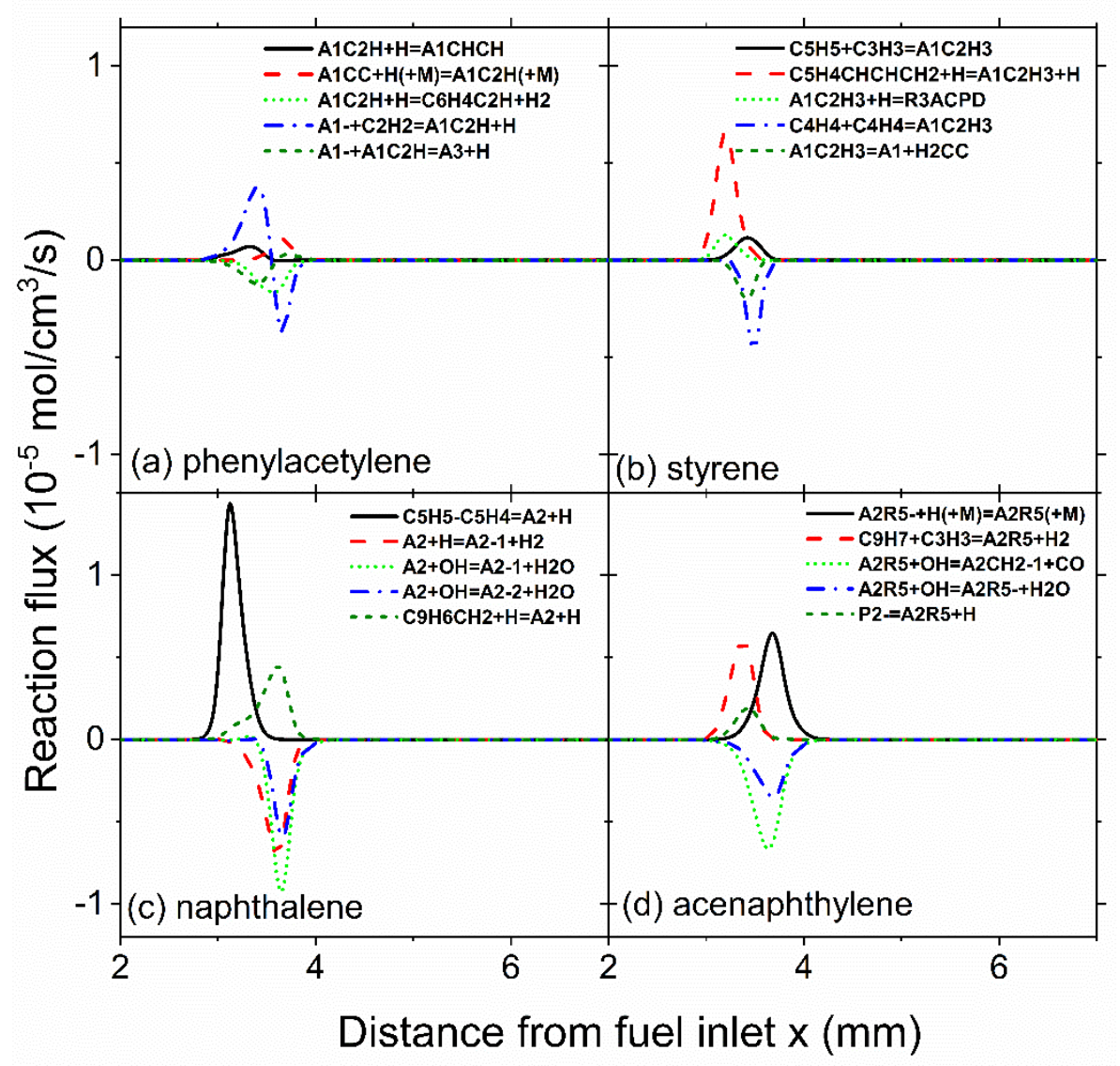

Figure 11: Rate of production analysis of phenylacetylene (a), styrene (b), naphthalene (c), and acenaphthylene (d) in the $\mathrm{CO}_{2} \mathrm{~F}$-flame.

\subsection{Oxygenated polycyclic aromatic hydrocarbons (OPAH)}

The mole fraction profiles of the detected OPAH molecules, i.e., phenol, benzaldehyde, cresol, ethyl-2-phenol, benzofuran, and dibenzofuran are presented in Fig. 12 and Fig. 13 for the $\mathrm{CO}_{2} \mathrm{~F}$-flame and $\mathrm{CO}_{2} \mathrm{O}$-flame, respectively. In both flames, good agreement between the two measurement techniques was achieved again for phenol. In the previous literature [7, 23], the separation of cresol isomers was not possible, and they were lumped as one specie in the kinetic models $[7,19,23]$. In this work, we were able to separate two cresol isomers, i.e., ocresol and p-cresol, and quantify them with the GC-MS (see Fig. 2). This new insight may allow future studies to investigate the different formation pathways of o-cresol and p-cresol and their influence on the formation of OPAH since a different growth propensity to OPAH is 
expected due to the site effect of the methyl and hydroxy group. Their relevance as important intermediates in anisole combustion is highlighted by their high mole fractions (Fig. 12c and Fig. 13c).

From the comparison of kinetic model simulations and experiments in both $\mathrm{CO}_{2} \mathrm{~F}$-flame and $\mathrm{CO}_{2} \mathrm{O}$-flame, the mole fraction profiles of phenol (Fig. 12a and Fig. 13a), benzaldehyde (Fig. 12b and Fig. 13b), and ethyl-2-phenol (Fig.12d and Fig. 13d) are in good agreement. Cresol is under-predicted by the model (Fig. 12c and 13c), and benzofuran (Fig. 12e and Fig. 13e) and dibenzofuran (Fig. 12f and Fig. 13f) are over-predicted, indicating inaccurate rate coefficients of the dominant production/consumption pathways or missing competing pathways. The rate of production analysis in Fig. 14 for the $\mathrm{CO}_{2}$ F-flame and Fig. S4 in Supplementary Material-1 for the $\mathrm{CO}_{2} \mathrm{O}$-flame reveal similar key formation/production pathways in both flames. The rate coefficients of dominant cresol formation pathways were adopted from Koirala et al. [53]. The separate treatment for $\mathrm{o}$-cresol and p-cresol in future studies will help to improve their predictions. For benzofuran, the most important reaction is $\mathrm{A} 1 \mathrm{O}+\mathrm{C}_{2} \mathrm{H}_{2} \Leftrightarrow \mathrm{C}_{8} \mathrm{H}_{6} \mathrm{O}$, and the rate coefficients were estimated by analogy to the HACA mechanism for PAH growth [51], which can be updated with the calculations by quantum chemistry in our recent work [54]. Dibenzofuran is mainly produced by the recombination of two phenoxy radicals [53], and the rate coefficients may be over-estimated. Revisiting the rate coefficients of the benzofuran and dibenzofuran formation pathways may help to improve the predictions. The tentative model update in the following section provides a good example for model improvement. 


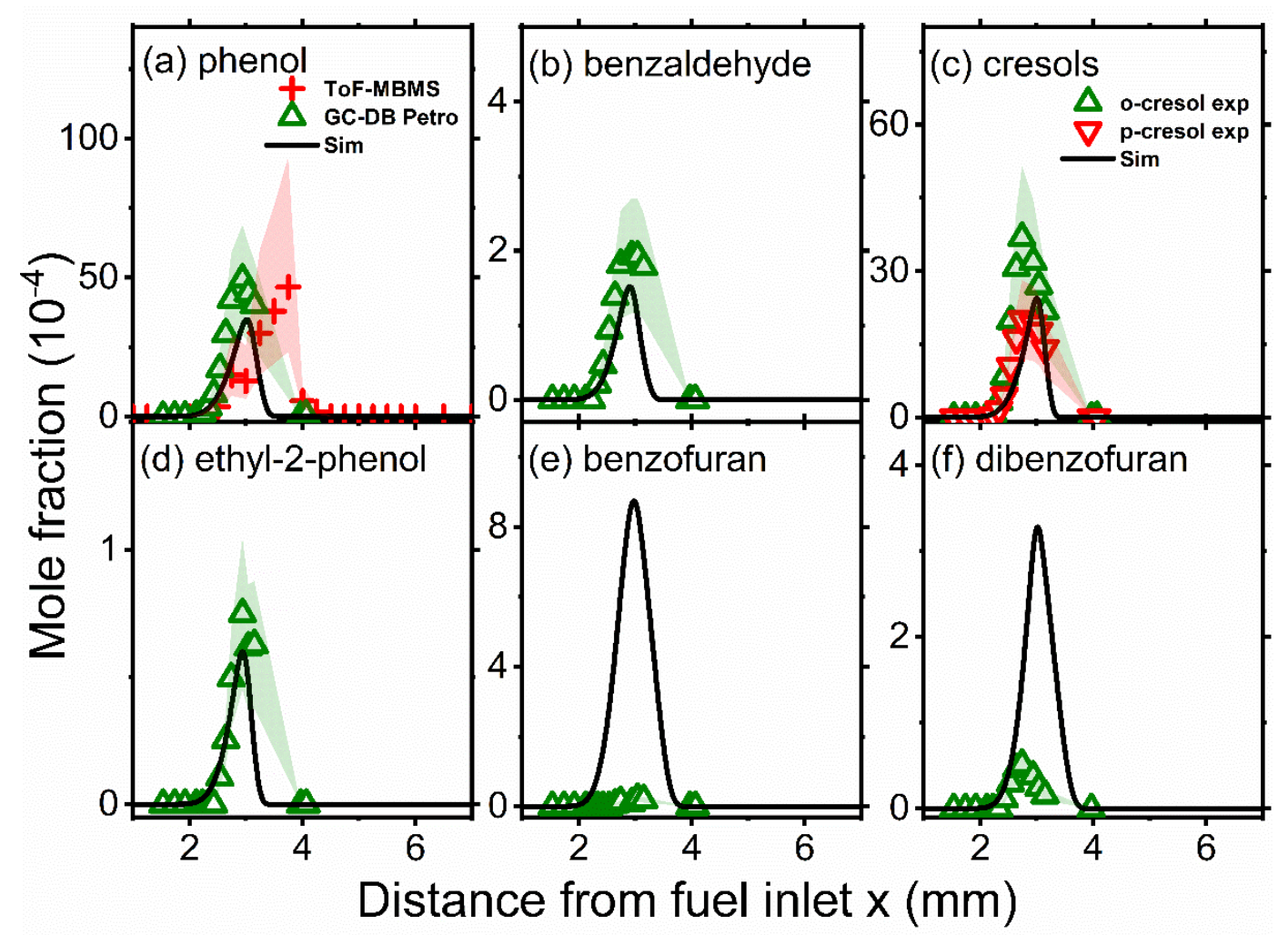

Figure 12: Mole fraction profiles of $\mathrm{OPAH}$ in the $\mathrm{CO}_{2} \mathrm{~F}-$ flame. Legends: the red crosses from ToF-MBMS; green triangles from GC-MS with the DB-Petro column; and solid black lines from the kinetic model simulations. Shaded areas with different colors indicate the measurement uncertainty of the respective techniques. 


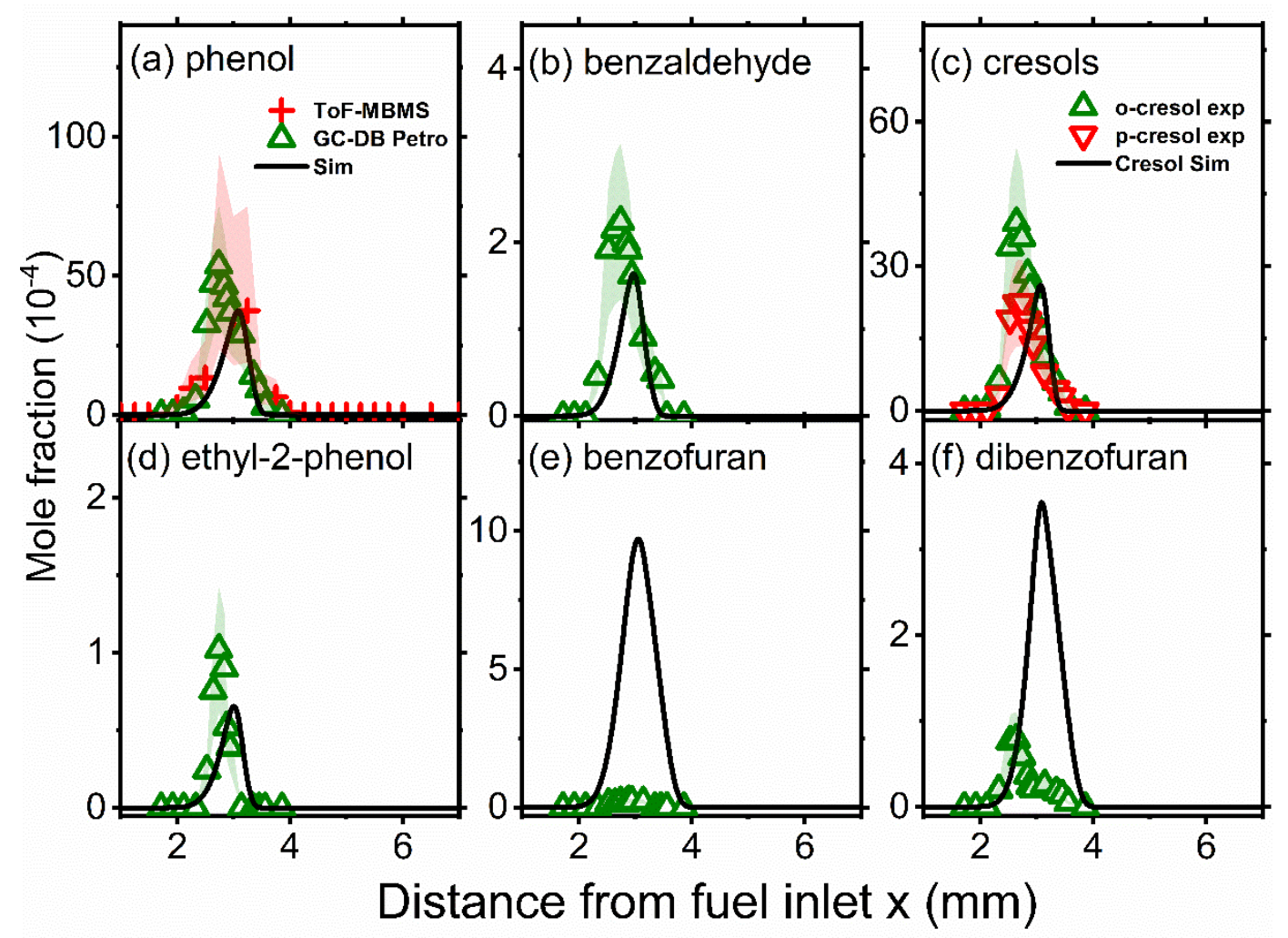

Figure 13: Mole fraction profiles of $\mathrm{OPAH}$ in the $\mathrm{CO}_{2} \mathrm{O}$-flame. Legends: the red crosses from ToF-MBMS; green triangles from GC-MS with the DB-Petro column; and solid black lines from the kinetic model simulations. Shaded areas with different colors indicate the measurement uncertainty of the respective techniques.
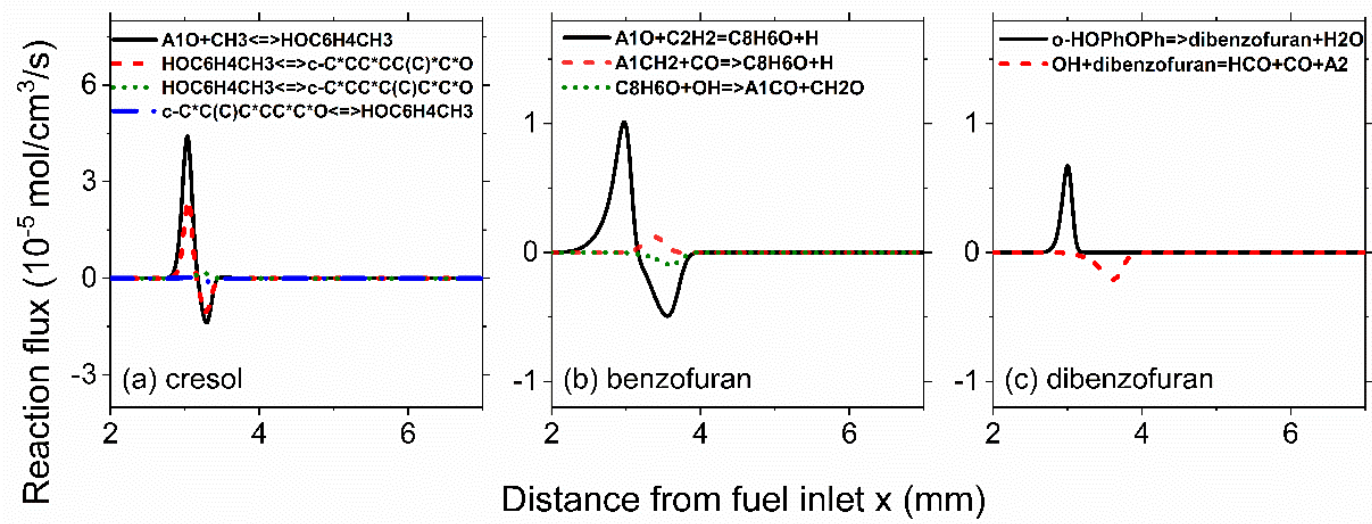

Figure 14: Rate of production analysis of cresol (a), benzofuran (b), and dibenzofuran (c) in the $\mathrm{CO}_{2} \mathrm{~F}$-flame.

\subsection{Tentative kinetic model update for PAH and OPAH chemistry}


Motivated by the highlighted reactions from model analyses for the PAH and OPAH molecules, we tentatively updated the kinetic model to check the influence on predictions. In the updated model, the base model was kept the same as Yuan et al. [19], and the PAH and OPAH chemistry was replaced by the chemistry from more recent work [46, 48, 50, 54-56], where the detailed reaction rate comparisons are also discussed and included. The Chemkin format of kinetic model files (kinetics, thermo, transport, and species glossary) is included in Supplementary Material-3 for reference. Please note that the tentative model update is not to propose a new model, but rather to point out a direction for future kinetic model development.

As shown in Fig. 15 for the $\mathrm{CO}_{2} \mathrm{~F}$-flame, the comparison of simulation results by using the two kinetic models and the experimental data shows that the predictions of benzofuran (Fig. 15a) are improved. The dominant benzofuran formation pathway in the updated model is the same as that in Yuan's model [19], which is A1O $+\mathrm{C}_{2} \mathrm{H}_{2} \Leftrightarrow \mathrm{C}_{8} \mathrm{H}_{6} \mathrm{O}$. In our previous work [56], the energy barrier of addition reaction $\mathrm{A} 1 \mathrm{O}+\mathrm{C}_{2} \mathrm{H}_{2}$ evaluated using $\mathrm{CCSD}(\mathrm{T}) / \mathrm{cc}-\mathrm{pvdz}$ method is $20.8 \mathrm{kcal} / \mathrm{mol}$, which is higher than the value in a typical HACA addition reaction (PAH radical $+\mathrm{C}_{2} \mathrm{H}_{2}$ ) by 7 times. The reaction rate coefficients were used in analogy to the HACA addition reaction rate coefficients in Yuan's model [19], which explains the overprediction of benzofuran. The predictions for PAH molecules, i.e., naphthalene (Fig. 15b) and acenaphthylene (Fig. 15c), are also improved. The predictions of styrene and ethylbenzene become worse with the updated model, which may be caused by the updated cyclopentadienyl radical recombination pathways from Cavalotti et al. [50]. The reduced reaction rate of $\mathrm{C}_{5} \mathrm{H}_{5}$ $+\mathrm{C}_{5} \mathrm{H}_{5} \Leftrightarrow \mathrm{C}_{5} \mathrm{H}_{5}-\mathrm{C}_{5} \mathrm{H}_{4}+\mathrm{H}$ could increase the participation of the cyclopentadienyl radical in the styrene formation pathway $\mathrm{C}_{5} \mathrm{H}_{5}+\mathrm{C}_{3} \mathrm{H}_{3} \Leftrightarrow \mathrm{C}_{6} \mathrm{H}_{5} \mathrm{C}_{2} \mathrm{H}_{3}$ as highlighted in the rate of production analysis of styrene (see Fig. 11b) and similarly for ethylbenzene. It should be noted that the formation pathway of ethylbenzene (Fig. 15f) is not considered in our previous work [54-56] and is inherited from Yuan's model [19]. Similar observations were found for the 
$\mathrm{CO}_{2} \mathrm{O}$-flame as shown in Fig. S5 in Supplementary Material-1. For the small key intermediates in PAH formation, e.g., acetylene (Fig. 15g), CO (Fig. 15h), and benzene (Fig. 15i), there are little differences between Yuan's model [19] and the updated model because of the same base chemistry. The examination of the tentative model update shows that by updating the PAH and OPAH chemistry the predictions of PAH and OPAH molecules can be improved.

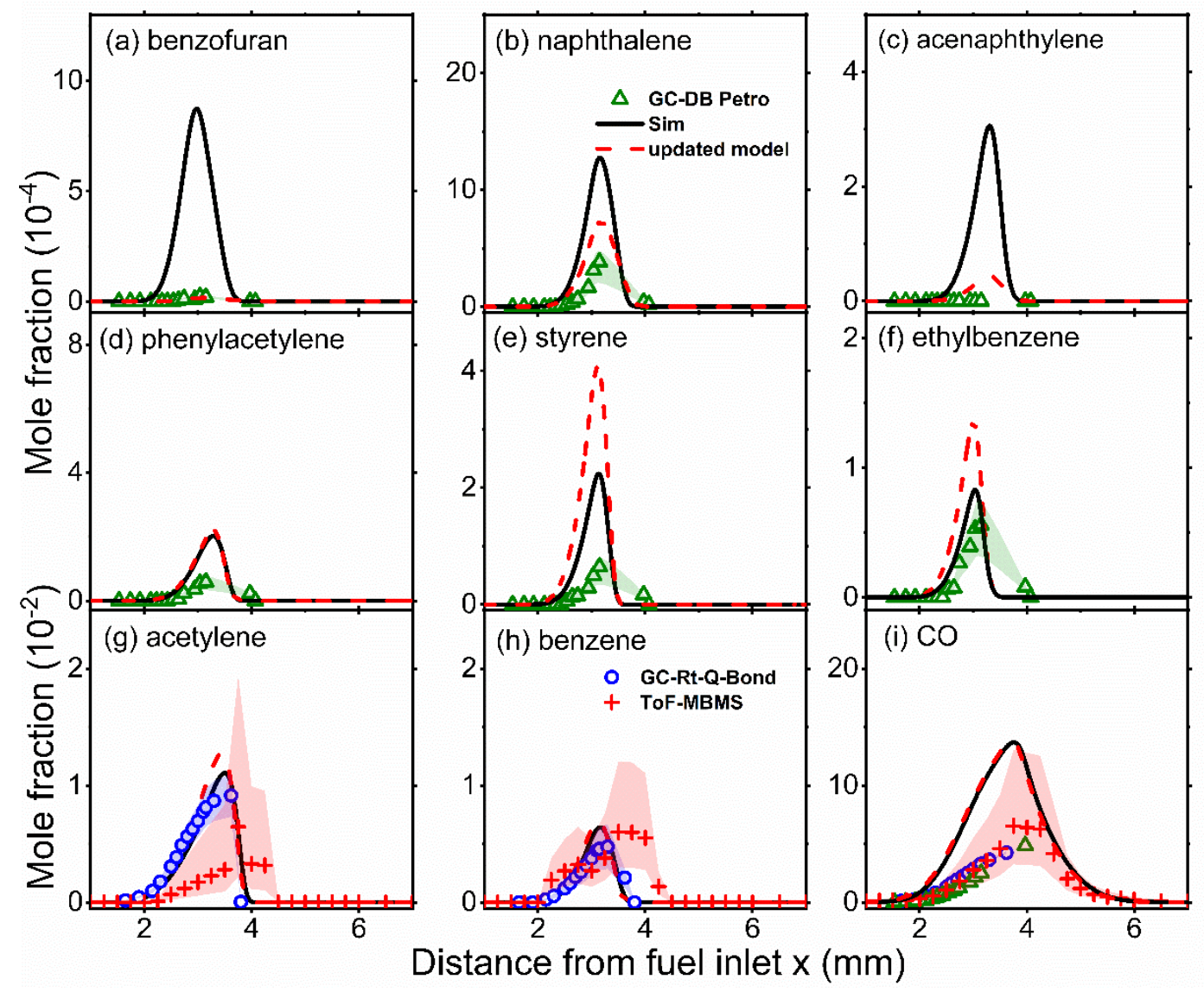

Figure 15: Comparison of species profile from experiments and simulations using the updated model and Yuan's model [19] in the $\mathrm{CO}_{2}$ F-flame. Legends: black solid lines are simulations using the model from Yuan et al. [19]; red dashed lines are simulations using the updated model in this work; red crosses from ToF-MBMS; the blue circles from GC-MS with the Rt-Q-Bond column; green triangles from GC-MS with the DB-Petro column. Shaded areas with different colors indicate the measurement uncertainty of the respective techniques.

\section{Conclusions}


In this work, a comprehensive speciation investigation was performed in two selected counterflow diffusion flames under oxy-fuel conditions to explore the combustion chemistry of anisole. Two experimental measurement techniques, i.e., ToF-MBMS and GC-MS, were applied to analyze the chemical composition throughout the flame. To the best of our knowledge, this is the first comprehensive investigation of anisole combustion chemistry in either counterflow diffusion flames or oxy-fuel conditions.

The three experimental datasets from ToF-MBMS, GC-MS with Rt-Q Bond column, and GC-MS with DB-Petro column were found in good agreement for most of the detected species. The numerical simulation results obtained by using the latest kinetic model matched the majority of the experimental results. However, for some species, the simulation results did not match well with the experiments, and further model analyses were performed to identify the responsible reactions.

The model analysis for $\mathrm{CO}$ and $\mathrm{CO}_{2}$ revealed similar sensitive reactions for $\mathrm{CO}$ production and $\mathrm{CO}_{2}$ consumption and inaccurate rate coefficients of these reactions may be responsible for the mismatch. The other possibility is that with a large amount of $\mathrm{CO}_{2}$ the over-predicted $\mathrm{H}$ radical may shift the chemical equilibrium of $\mathrm{CO}+\mathrm{OH} \Leftrightarrow \mathrm{CO}_{2}+\mathrm{H}$ to the reactant side. The over-predictions of some aromatic and PAH molecules (i.e., phenylacetylene, styrene, naphthalene, and acenaphthylene), and OPAH molecules (i.e., cresol isomers, benzofuran, and dibenzofuran) were found to be caused by the inaccurate rate coefficients in their dominant production/consumption pathways as revealed by model analyses. A tentative model update showed the potential to improve the predictions for PAH and OPAH molecules. The experimental datasets and kinetic model analysis in this work will be valuable to further shed light on the biomass oxy-fuel combustion chemistry in practical applications.

\section{Acknowledgements}


The authors acknowledge the financial support by the Deutsche Forschungsgemeinschaft within the framework of the collaborative research center SFB/Transregio 129 "Oxyflame". The work was further supported by the Deutsche Forschungsgemeinschaft (DFG, German Research Foundation) under Germany's Excellence Strategy - Cluster of Excellence 2186 „The Fuel Science Center” - ID: 390919832. The calculation work in this paper was supported by the funding from King Abdullah University of Science and Technology (KAUST) and Clean Combustion Research Center (CCRC). LC would like to further thank the support by the Fundamental Research Funds for the Central Universities.

\section{References}

[1] S. Chu, A. Majumdar, Opportunities and challenges for a sustainable energy future, Nature 488 (2012) 294.

[2] M. B. Toftegaard, J. Brix, P. A. Jensen, P. Glarborg, A. D. Jensen, Oxy-fuel combustion of solid fuels, Prog. Energy Combust. Sci. 36 (2010) 581-625.

[3] F. Sher, M. A. Pans, C. Sun, C. Snape, H. Liu, Oxy-fuel combustion study of biomass fuels in a $20 \mathrm{kWth}$ fluidized bed combustor, Fuel 215 (2018) 778-786.

[4] F. Alobaid, J.-P. Busch, A. Stroh, J. Ströhle, B. Epple, Experimental measurements for torrefied biomass Co-combustion in a 1 MWth pulverized coal-fired furnace, J. Energy Inst. 93 (2020) 833-846.

[5] K. Kohse - Höinghaus, P. Oßwald, T. A. Cool, T. Kasper, N. Hansen, F. Qi, C. K. Westbrook, P. R. Westmoreland, Biofuel combustion chemistry: from ethanol to biodiesel, Angew. Chem. Int. Ed. 49 (2010) 3572-3597.

[6] W. Leitner, J. Klankermayer, S. Pischinger, H. Pitsch, K. Kohse - Höinghaus, Advanced biofuels and beyond: chemistry solutions for propulsion and production, Angew. Chem. Int. Ed. 56 (2017) 5412-5452. 
[7] S. W. Wagnon, S. Thion, E. J. Nilsson, M. Mehl, Z. Serinyel, K. Zhang, P. Dagaut, A. A. Konnov, G. Dayma, W. J. Pitz, Experimental and modeling studies of a biofuel surrogate compound: laminar burning velocities and jet-stirred reactor measurements of anisole, Combust. Flame 189 (2018) 325-336.

[8] R. Büttgen, M. Tian, Y. Fenard, H. Minwegen, M. Boot, K. Heufer, An experimental, theoretical and kinetic modelling study on the reactivity of a lignin model compound anisole under engine-relevant conditions, Fuel 269 (2020) 117190.

[9] J. Herzler, M. Fikri, C. Schulz, Ignition delay time study of aromatic LIF tracers in a wide temperature and pressure range, International Colloquium on the Dynamics of Explosions and Reactive Systems (ICDERS), Boston, MA (2017)

[10] C.-Y. Lin, M. Lin, Thermal decomposition of methyl phenyl ether in shock waves: The kinetics of phenoxy radical reactions, J. Phys. Chem. 90 (1986) 425-431.

[11] S. Zabeti, M. Aghsaee, M. Fikri, O. Welz, C. Schulz, Optical properties and pyrolysis of shock-heated gas-phase anisole, Proc. Combust. Inst. 36 (2017) 4525-4532.

[12] Y. Wu, B. Rossow, V. Modica, X. Yu, L. Wu, F. Grisch, Laminar flame speed of lignocellulosic biomass-derived oxygenates and blends of gasoline/oxygenates, Fuel $202(2017) 572-582$.

[13] S. Zare, S. Roy, A. El Maadi, O. Askari, An investigation on laminar burning speed and flame structure of anisole-air mixture, Fuel 244 (2019) 120-131.

[14] I. W. Arends, R. Louw, P. Mulder, Kinetic study of the thermolysis of anisole in a hydrogen atmosphere, J. Phys. Chem. 97 (1993) 7914-7925.

[15] A. V. Friderichsen, E.-J. Shin, R. J. Evans, M. R. Nimlos, D. C. Dayton, G. B. Ellison, The pyrolysis of anisole (C6H5OCH3) using a hyperthermal nozzle, Fuel 80 (2001) 1747-1755. 
[16] M. Pecullan, K. Brezinsky, I. Glassman, Pyrolysis and oxidation of anisole near 1000 K, J. Phys. Chem. A 101 (1997) 3305-3316.

[17] M. Pelucchi, T. Faravelli, A. Frassoldati, E. Ranzi, G. Sribala, G. B. Marin, K. M. Van Geem, Experimental and kinetic modeling study of pyrolysis and combustion of anisole, Chem. Eng. Trans. 65 (2018) 127-132.

[18] A. M. Scheer, C. Mukarakate, D. J. Robichaud, G. B. Ellison, M. R. Nimlos, Radical chemistry in the thermal decomposition of anisole and deuterated anisoles: An investigation of aromatic growth, J. Phys. Chem. A 114 (2010) 9043-9056.

[19] W. Yuan, T. Li, Y. Li, M. Zeng, Y. Zhang, J. Zou, C. Cao, W. Li, J. Yang, F. Qi, Experimental and kinetic modeling investigation on anisole pyrolysis: Implications on phenoxy and cyclopentadienyl chemistry, Combust. Flame 201 (2019) 187-199.

[20] T. Zhang, C. Bhattarai, Y. Son, V. Samburova, A. Khlystov, S. A. Varganov, Reaction Mechanisms of Anisole Pyrolysis at Different Temperatures: Experimental and Theoretical Studies, Energy Fuels 35 (2021) 9994-10008.

[21] B. Chen, S. Kruse, R. Schmid, L. Cai, N. Hansen, H. Pitsch, Oxygenated PAH Formation Chemistry Investigation in Anisole Jet Stirred Reactor Oxidation by a Thermodynamic Approach, Energy Fuels 35 (2021) 1535-1545.

[22] J. Mackie, K. Doolan, P. Nelson, Kinetics of the thermal decomposition of methoxybenzene (anisole), J. Phys. Chem. 93 (1989) 664-670.

[23] M. Nowakowska, O. Herbinet, A. Dufour, P.-A. Glaude, Detailed kinetic study of anisole pyrolysis and oxidation to understand tar formation during biomass combustion and gasification, Combust. Flame 161 (2014) 1474-1488.

[24] T. Bierkandt, P. Hemberger, P. Oßwald, D. Krüger, M. Köhler, T. Kasper, Flame structure of laminar premixed anisole flames investigated by photoionization mass 
spectrometry and photoelectron spectroscopy, Proc. Combust. Inst. 37 (2019) 15791587.

[25] M. Pelucchi, C. Cavallotti, A. Cuoci, T. Faravelli, A. Frassoldati, E. Ranzi, Detailed kinetics of substituted phenolic species in pyrolysis bio-oils, Reaction Chemistry \& Engineering 4 (2019) 490-506.

[26] M. Baroncelli, D. Felsmann, N. Hansen, H. Pitsch, Investigating the effect of oxy-fuel combustion and light coal volatiles interaction: A mass spectrometric study, Combust. Flame 204 (2019) 320-330.

[27] M. Baroncelli, Q. Mao, S. Galle, N. Hansen, H. Pitsch, Role of ring-enlargement reactions in the formation of aromatic hydrocarbons, Phys. Chem. Chem. Phys. 22 (2020) 4699-4714.

[28] M. Baroncelli, Q. Mao, H. Pitsch, N. Hansen, Effects of C1-C3 hydrocarbon blending on aromatics formation in 1-butene counterflow flames, Combust. Flame 230 (2021) 111427.

[29] K. Seshadri, F. Williams, Laminar flow between parallel plates with injection of a reactant at high Reynolds number, Int. J. Heat Mass Transfer 21 (1978) 251-253.

[30] J. Emmert, M. Baroncelli, H. Pitsch, S. Wagner, Axisymmetric linear hyperspectral absorption spectroscopy and residuum-based parameter selection on a counter flow burner, Energies 12 (2019) 2786.

[31] Y. Kim, K. Irikura, M. Rudd, M. Ali, P. Stone, J. Chang, J. Coursey, R. Dragoset, A. Kishore, K. Olsen, Electron-Impact Ionization Cross Section for Ionization and Excitation Database (version 3.0, 2004), URL http://www. nist. gov/pml/data/ionization/index. cfm (2008)

[32] F. Carbone, F. Cattaneo, A. Gomez, Structure of incipiently sooting partially premixed ethylene counterflow flames, Combust. Flame 162 (2015) 4138-4148. 
[33] F. Carbone, K. Gleason, A. Gomez, Pressure effects on incipiently sooting partially premixed counterflow flames of ethylene, Proc. Combust. Inst. 36 (2017) 1395-1402.

[34] L. Figura, F. Carbone, A. Gomez, Challenges and artifacts of probing high-pressure counterflow laminar diffusion flames, Proc. Combust. Inst. 35 (2015) 1871-1878.

[35] L. Figura, A. Gomez, Structure of incipiently sooting ethylene-nitrogen counterflow diffusion flames at high pressures, Combust. Flame 161 (2014) 1587-1603.

[36] K. Gleason, F. Carbone, A. J. Sumner, B. D. Drollette, D. L. Plata, A. Gomez, Small aromatic hydrocarbons control the onset of soot nucleation, Combust. Flame 223 (2021) 398-406.

[37] C. Faiola, M. Erickson, V. Fricaud, B. Jobson, T. M. Vanreken, Quantification of biogenic volatile organic compounds with a flame ionization detector using the effective carbon number concept, Atmos. Meas. Tech. 5 (2012) 1911-1923.

[38] T. Holm, Mechanism of the flame ionization detector II. Isotope effects and heteroatom effects, J. Chromatogr. A 782 (1997) 81-86.

[39] R. Kee, F. Rupley, J. Miller, M. Coltrin, J. Grcar, E. Meek, H. Moffat, A. Lutz, G. Dixon-Lewis, M. Smooke, Chemkin-Pro, ANSYS reaction design. 2008: San Diego, CA.

[40] L. P. Maffei, M. Pelucchi, T. Faravelli, C. Cavallotti, Theoretical study of sensitive reactions in phenol decomposition, Reaction Chemistry \& Engineering 5 (2020) 452472.

[41] K. Wang, S. M. Villano, A. M. Dean, Experimental and kinetic modeling study of butene isomer pyrolysis: Part I. 1-and 2-Butene, Combust. Flame 173 (2016) 347-369.

[42] G. P. Smith, D. M. Golden, M. Frenklach, N. W. Moriarty, B. Eiteneer, M. Goldenberg, C. T. Bowman, R. K. Hanson, S. Song, W. C. Gardiner, V. V. Lissianski, Z. Qin. GRIMech 3.0. Available from: http://www.me.berkeley.edu/gri_mech/. 
[43] C.-W. Zhou, Y. Li, U. Burke, C. Banyon, K. P. Somers, S. Ding, S. Khan, J. W. Hargis, T. Sikes, O. Mathieu, An experimental and chemical kinetic modeling study of 1, 3butadiene combustion: Ignition delay time and laminar flame speed measurements, Combust. Flame 197 (2018) 423-438.

[44] Y. Wu, S. Panigrahy, A. B. Sahu, C. Bariki, J. Beeckmann, J. Liang, A. A. Mohamed, S. Dong, C. Tang, H. Pitsch, Understanding the antagonistic effect of methanol as a component in surrogate fuel models: A case study of methanol/n-heptane mixtures, Combust. Flame 226 (2021) 229-242.

[45] H. Wang, Formation of nascent soot and other condensed-phase materials in flames, Proc. Combust. Inst. 33 (2011) 41-67.

[46] P. Liu, Z. Li, A. Bennett, H. Lin, S. M. Sarathy, W. L. Roberts, The site effect on PAHs formation in HACA-based mass growth process, Combust. Flame 199 (2019) 54-68.

[47] Q. Mao, L. Cai, R. Langer, H. Pitsch, The role of resonance-stabilized radical chain reactions in polycyclic aromatic hydrocarbon growth: Theoretical calculation and kinetic modeling, Proc. Combust. Inst. 38 (2021) 1459-1466.

[48] A. Mebel, V. Kislov, Can the C5H5+ C5H5 $\rightarrow \mathrm{C} 10 \mathrm{H} 10 \rightarrow \mathrm{C} 10 \mathrm{H} 9+\mathrm{H} / \mathrm{C} 10 \mathrm{H} 8+\mathrm{H} 2$ reaction produce naphthalene? An ab initio/RRKM study, J. Phys. Chem. A 113 (2009) 9825-9833.

[49] A. E. Long, S. S. Merchant, A. G. Vandeputte, H.-H. Carstensen, A. J. Vervust, G. B. Marin, K. M. Van Geem, W. H. Green, Pressure dependent kinetic analysis of pathways to naphthalene from cyclopentadienyl recombination, Combust. Flame 187 (2018) 247256.

[50] C. Cavallotti, D. Polino, On the kinetics of the C5H5+C5H5 reaction, Proc. Combust. Inst. 34 (2013) 557-564. 
[51] M. Frenklach, Reaction mechanism of soot formation in flames, Phys. Chem. Chem. Phys. 4 (2002) 2028-2037.

[52] G. Blanquart, P. Pepiot-Desjardins, H. Pitsch, Chemical mechanism for high temperature combustion of engine relevant fuels with emphasis on soot precursors, Combust. Flame 156 (2009) 588-607.

[53] Y. Koirala, Investigating the kinetics of anisole: a simple lignin model compound. (2015) Colorado School of Mines. Arthur Lakes Library

[54] P. Liu, B. Chen, Z. Li, A. Bennett, S. Sioud, S. M. Sarathy, W. L. Roberts, Evolution of oxygenated polycyclic aromatic hydrocarbon chemistry at flame temperatures, Combust. Flame 209 (2019) 441-451.

[55] P. Liu, Z. Li, W. L. Roberts, Growth network of PAH with 5-membered ring: Case study with acenaphthylene molecule, Combust. Flame 230 (2021) 111449.

[56] P. Liu, B. Chen, Z. Li, A. Bennett, S. Sioud, H. Pitsch, S. M. Sarathy, W. L. Roberts, Experimental and Theoretical Evidence for the Temperature-determined Evolution of PAH Functional Groups Proc. Combust. Inst. 38 (2021) 1467-1475. 